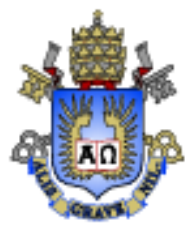

Felipe Reis Gomes

Classificação de ofertas de produtos

Dissertação apresentada como requisito parcial para obtenção do grau de Mestre pelo Programa de Pós-graduação em Informática do Departamento de Informática da PUC-Rio

Orientador : Prof. Marco Antonio Casanova Co-Orientador: Prof. Ruy Luiz Milidiú 
Felipe Reis Gomes

\title{
Classificação de ofertas de produtos
}

Dissertação apresentada como requisito parcial para obtenção do grau de Mestre pelo Programa de Pós-graduação em Informática do Departamento de Informática do Centro Técnico Científico da PUC-Rio. Aprovada pela Comissão Examinadora abaixo assinada.

\author{
Prof. Marco Antonio Casanova \\ Orientador \\ Departamento de Informática — PUC-Rio
}

Prof. Ruy Luiz Milidiú

Co-Orientador

Departamento de Informática - PUC-Rio

Prof. Antônio Luz Furtado

Departamento de Informática — PUC-Rio

Prof. Helio Cortes Vieira Lopes

Departamento de Informática — PUC-Rio

Prof. José Eugenio Leal Coordenador Setorial do Centro Técnico Científico - PUC-Rio

Rio de Janeiro, 18 de Dezembro de 2012 
Todos os direitos reservados. É proibida a reprodução total ou parcial do trabalho sem autorização da universidade, do autor e do orientador.

\section{Felipe Reis Gomes}

Graduou-se no curso de Bacharelado em Informática pela Pontifícia Universidade Católica do Rio de Janeiro. Trabalhou desenvolvendo sistemas de localização geográfica de veículos no TecGraf. Trabalhou na GAPSO - empresa da área de otimização de logística construindo um framework de desenvolvimento seguindo as melhores práticas do mercado e na RiskControl - empresa do mercado financeiro. Atual líder técnico do departamento de Desenvolvimento de Sistemas da FINEP (Financiadora de Estudos e Projetos), onde é responsável por definir os padrões de trabalho e as tecnologias que serão utilizadas pelo departamento e pelos fornecedores da empresa.

Ficha Catalográfica

Gomes, Felipe Reis

Classificação de ofertas de produtos / Felipe Reis Gomes; orientador: Marco Antonio Casanova; co-orientador: Ruy Luiz Milidiú. - Rio de Janeiro : PUC-Rio, Departamento de Informática, 2012.

v., 84 f: il. ; $29,7 \mathrm{~cm}$

1. Dissertação (mestrado) - Pontifícia Universidade Católica do Rio de Janeiro, Departamento de Informática.

Inclui referências bibliográficas.

1. Informática - Tese. 2. Aprendizado de Máquina. 3. Aprendizado Supervisionado. 4. Classificação de Entidades. 5. Classificação de Produtos. 6. WEKA. 7. Framework Aprendizado de Máquina. I. Casanova, Marco Antonio. II. Milidiú, Ruy Luiz. III. Furtado, Antônio Luz. IV. Lopes, Helio Cortes Vieira. V. Pontifícia Universidade Católica do Rio de Janeiro. Departamento de Informática. VI. Título. 


\section{Agradecimentos}

A Deus por me guiar durante toda a minha vida.

Aos meus orientadores Marco Antonio Casanova e Ruy Luiz Milidiú, por terem partilhado comigo dos seus valorosos ensinamentos.

À PUC-Rio e ao TecGraf pelos auxílios concedidos, sem os quais não seria possível realizar este trabalho.

À minha esposa e aos meus familiares, que me apoiaram durante todo o tempo e souberam compreender as minhas ausências ao longo desses anos.

Aos meus amigos que me deram força para transpor os muitos obstáculos encontrados pelo caminho. 


\section{Resumo}

Gomes, Felipe Reis; Casanova, Marco Antonio; Milidiú, Ruy Luiz.

Classificação de ofertas de produtos. Rio de Janeiro, 2012. 84p. Dissertação de Mestrado — o de Informática, Pontifícia Universidade Católica do Rio de Janeiro.

Este trabalho apresenta o EasyLearn, um framework para apoiar o desenvolvimento de aplicações voltadas ao aprendizado supervisionado. $\mathrm{O}$ EasyLearn define uma camada intermediaria, de simples configuração e entendimento, entre a aplicação e o WEKA, um framework de aprendizado de máquina criado pela Universidade de Waikato. Todos os classificadores e filtros implementados pelo WEKA podem ser facilmente encapsulados para serem utilizados pelo EasyLearn. O EasyLearn recebe como entrada um conjunto de arquivos de configuração no formato XML contendo a definição do fluxo de processamento a ser executado, além da fonte de dados a ser processada, independente do formato. Sua saída é adaptável e pode ser configurada para produzir, por exemplo, relatórios de acurácia da classificação, a própria da fonte de dados classificada, ou o modelo de classificação já treinado. A arquitetura do EasyLearn foi definida após a análise detalhada dos processos de classificação, permitindo identificar inúmeras atividades em comum entre os três processos estudados (aprendizado, avaliação e classificação). Através desta percepção e tomando as linguagens orientadas a objetos como inspiração, foi criado um framework capaz de comportar os processos de classificação e suas possíveis variações, além de permitir o reaproveitamento das configurações, através da implementação de herança e polimorfismo para os seus arquivos de configuração. A dissertação ilustra o uso do framework criado através de um estudo de caso completo sobre classificação de produtos do comércio eletrônico, incluindo a criação do corpus, engenharia de atributos e análise dos resultados obtidos.

\section{Palavras-chave}

Aprendizado de Máquina; Aprendizado Supervisionado; Classificação de Entidades; Classificação de Produtos; WEKA; Framework Aprendizado de Máquina; 


\section{Abstract}

Gomes, Felipe Reis; Casanova, Marco Antonio; Milidiú, Ruy Luiz.

Product Offering Classification. Rio de Janeiro, 2012. 84p. MSc Dissertation - Departamento de Informática, Pontifícia Universidade Católica do Rio de Janeiro.

This dissertation presents EasyLearn, a framework to support the development of supervised learning applications. EasyLearn defines an intermediate layer, which is easy to configure and understand, between the application and WEKA, a machine learning framework created by the University of Waikato. All classifiers and filters implemented by WEKA can be easily encapsulated to be used by EasyLearn. EasyLearn receives as input a set of configuration files in XML format containing the definition of the processing flow to be executed, in addition to the data source to be classified, regardless of format. Its output is customizable and can be configured to produce classification accuracy reports, the classified data source, or the trained classification model. The architecture of EasyLearn was defined after a detailed analysis of the classification process, which identified a set of common activities among the three analyzed processes (learning, evaluation and classification). Through this insight and taking the object-oriented languages as inspiration, a framework was created which is able to support the classification processes and its variations, and which also allows reusing settings by implementing inheritance and polymorphism in their configuration files. This dissertation also illustrates the use of the created framework presenting a full case study about e-commerce product classification, including corpus creation, attribute engineering and result analysis.

\section{Keywords}

Machine Learning; Supervised Learning; Entity Classification; Product Classification; WEKA; Machine Learning Framework; 


\section{Sumário}

1 Introdução $\quad 10$

2 Fundamentos $\quad 13$

2.1 Classificação 13

2.2 Aprendizado Supervisionado 14

2.3 Aprendizado Não-supervisionado 14

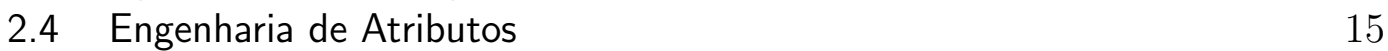

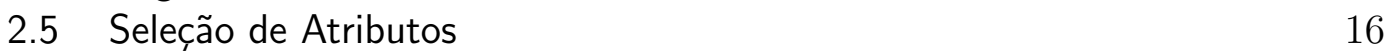

2.6 Trabalhos Relacionados 16

3 Processos de Aprendizado Supervisionado 18

$\begin{array}{lll}3.1 & \text { Pre-requisitos } & 18\end{array}$

3.2 Avaliação 18

3.3 Aprendizado 21

3.4 Classificação 22

3.5 Procedimentos de Pré-processamento 23

4 Arquitetura $\quad 31$

4.1 Requisitos 31

4.2 Conceitos 32

4.3 Pacotes e Classes do EasyLearn 33

4.4 Configuração 33

$\begin{array}{lll}4.5 & \text { Diagrama XSD } & 35\end{array}$

4.6 Elementos do XML de configuração 36

4.7 Exemplos de configurações 37

5 Estudo de Caso: Classificação Ofertas de Produtos 41

5.1 Requisitos 41

5.2 Corpus 41

$\begin{array}{lll}5.3 & \text { Resultados } & 46\end{array}$

6 Conclusão $\quad 51$

$\begin{array}{ll}\text { Referências Bibliográficas } & 54\end{array}$

A Classes do EasyLearn $\quad 57$

A.1 Pacote Matcher $\quad 57$

$\begin{array}{lll}\text { A.2 Pacote Matcher.Config } & 59\end{array}$

A.3 Pacote Matcher.KFlow 62

A.4 Pacote Matcher.KFlow.Source 64

A.5 Pacote Matcher.KFlow.Priori 66

A.6 Pacote Matcher.KFlow.Classifier $\quad 70$

A.7 Pacote Matcher.KFlow.Merger 73

A.8 Pacote Matcher.KFlow.Posteriori $\quad 75$

A.9 Pacote Matcher.Weka.Filter 78 
A.10 Pacote Matcher.Weka.Evaluation $\quad 80$

A.11 Pacote Debug $\quad 81$

B XML de Configuração: SPAM 


\section{Lista de figuras}

2.1 Exemplo de escrita manual digitalizada 13

3.1 Processo de avaliação 28

$\begin{array}{lll}3.2 & \text { Processo de aprendizado } & 29\end{array}$

3.3 Processo de classificação 30

4.1 Visão geral da Arquitetura do framework 33

4.2 XSD - KnowledgeFlow 35

$\begin{array}{ll}\text { 4.3 Estrutura do arquivo de entrada ARFF. } & 37\end{array}$

5.1 Categorias dos Produtos 43

5.2 Classe de produto Sony Bravia KDL-40BX425 43

5.3 Instâncias do produto Sony Bravia KDL-40BX425 em diversas lojas 44

A.1 Diagrama das classes do pacote Matcher 57

A.2 Diagrama das classes do pacote Matcher.Config $\quad 59$

A.3 Diagrama das classes do pacote Matcher.KFlow 62

A.4 Diagrama das classes do pacote Matcher.KFlow.Source 64

A.5 Diagrama das classes do pacote Matcher.KFlow.Priori 66

A.6 Diagrama das classes do pacote Matcher.KFlow.Classifier $\quad 70$

A.7 Diagrama das classes do pacote Matcher.KFlow.Merger $\quad 73$

A.8 Diagrama das classes do pacote Matcher.KFlow.Posteriori $\quad 75$

A.9 Diagrama das classes do pacote Matcher.Weka.Filter 78

A.10 Diagrama das classes do pacote Matcher.Weka.Evaluation $\quad 80$

A.11 Diagrama das classes do pacote Matcher.Debug 81 


\section{Lista de tabelas}

2.1 Representação vetorial das palavras 15

5.1 Maiores categorias 46 


\section{Introdução}

Após a revolução tecnológica proporcionada pela popularização da internet na década de 1990, inovadores modelos de negócio surgiram para rivalizar com as formas tradicionais de trabalho. Uma das evoluções mais notáveis trazidas pela grande rede foi o ecommerce que permitiu encurtar o caminho entre vendedores e compradores e tornou mais fácil o acesso à bens e serviços, independente das fronteiras entre os países.

Segundo um balanço semestral sobre a expansão do comércio eletrônico no Brasil emitido pela consultoria eBit, até o final do primeiro semestre de 2011 mais de 4000 mil lojas virtuais conquistaram o selo de confiança da empresa correspondendo a um aumento de $26 \%$ em relação ao mesmo período de 2010 (WebShoppers11). No país são mais de 23.000 lojas virtuais (eSchool11) comercializando milhões de produtos, juntas faturaram em 2010 mais de 14,5 bilhões de reais.

Infelizmente é difícil determinar a quantidade exata de SKU (Stock Keeping Units), que é terminologia usada para identificar de forma única as classes dos produtos comercializados (Tompkins98), pois não existe nenhum diretório unificado de lojas. No entanto, é possível ter uma noção da ordem de grandeza para a contagem de produtos quando observamos os catálogos das três maiores lojas virtuais da internet brasileira (Americanas, Submarino e Saraiva) que possuem mais de um milhão de produtos cadastrados.

Manter catálogos desta magnitude não é uma tarefa simples e agrega diversas subtarefas, como categorização dos produtos, busca por relevância, consolidação de catálogos distintos, detecção de duplicatas, entre outras.

O problema de classificação de produtos abordado neste trabalho pode ser definido da seguinte forma: dada uma série de descrições de ofertas de produtos, precisamos identificar quais descrições correspondem ao mesmo produto. Supondo que duas grandes empresas detentoras de web sites de ecommerce realizaram uma fusão de seus negócios e agora desejam mesclar seus catálogos. Como minimizar o trabalho manual na identificação dos produtos repetidos entre os catálogos?

Geralmente, as lojas disponibilizam grande parte da descrição e ca- 
racterísticas de um produto em seu nome de exibição. Assim, por exemplo, "MONIT LCD 19 ACER X193W WIDE PRETO" diz respeito a um monitor LCD, de 19 polegadas, da marca ACER, modelo X193W, widescreen de cor preta. Esse mesmo produto, em outra loja, tem a descrição "Monitor LCD Acer ETCX3WP004 X193W ABD 19 20.000:1". Note que a falta de estrutura na descrição do produto torna a tarefa mais difícil.

Neste trabalho utilizamos técnicas de aprendizado supervisionado para apresentar uma solução ao problema de classificação de ofertas de produtos do comércio eletrônico, cujo o objetivo é identificar se uma determinada oferta de um produto em uma loja virtual corresponde a um produto já catalogado previamente. Para cumprir o objetivo deste trabalho construímos um corpus para apoiar as técnicas de aprendizado supervisionado, realizamos a engenharia de atributos para extrair atributos relevantes a partir da descrição da oferta - que é o único atributo disponível à priori, e por fim, criamos o EasyLearn, um framework para apoiar o desenvolvimento de aplicações voltadas ao aprendizado supervisionado. Utilizamos o framework desenvolvido para resolver o problema supracitado de forma simples e elegante. Além disto, demonstramos o potencial da infra-estrutura criada apresentando outras aplicações relacionadas ao aprendizado supervisionado.

O EasyLearn define uma camada intermediaria - de simples configuração e entendimento - entre a aplicação e o WEKA (framework de Aprendizado de Máquina criado pela Universidade de Waikato). Todos os classificadores e filtros implementados pelo $W E K A$ podem ser facilmente encapsulados para serem utilizados pelo EasyLearn.

O EasyLearn recebe como entrada um conjunto de arquivos de configuração no formato XML. A composição destes arquivos irá definir o fluxo de processamento a ser executado, além do DataSource a ser processado - independente do formato. Sua saída é customizável e pode ser configurada para produzir, por exemplo, relatórios de acurácia da classificação, o próprio DataSource classificado, ou o modelo de classificação já treinado.

Os arquivos de configuração são baseados no domínio do problema a ser modelado. No anexo B vemos um exemplo de artefatos de configuração utilizados como entrada do EasyLearn.

A arquitetura do EasyLearn foi definida após a análise detalhada dos processos de Classificação, onde identificamos inúmeras atividades em comum entre os três processos estudados (aprendizado, avaliação e classificação). Através desta percepção e tomando as linguagens Orientadas à Objetos como inspiração, criamos um framework capaz de comportar os processos de classificação e suas possíveis variações, além de permitir o reaproveitamento 
das configurações, através da implementação de herança e polimorfismo para os seus arquivos de configuração.

Esta dissertação foi organizada da seguinte forma: o capítulo (2) apresenta alguns fundamentos e estratégias de Aprendizado de Máquina, incluindo alguns trabalhos relacionados. O capítulo 3 expõe os processos de classificação utilizados como base da construção do EasyLearn. O capítulo 4 fornece uma visão detalhada sobre a arquitetura do framework, juntamente com seu escopo e requisitos. O capítulo 5 exemplifica a utilização do framework em um estudo de caso real - que é o tema deste trabalho. Finalmente, o capítulo 6 conclui o estudo e relaciona alguns possíveis caminhos para dar continuidade à esta pesquisa. 


\section{2 \\ Fundamentos}

\section{1}

\section{Classificação}

Digamos que queremos reconhecer um número escrito à mão, digitalizado e salvo numa imagem, como visto na figura 2.1. Para cada algarismo, temos 10 possíveis respostas, de 0 à 9 . A caligrafia pode variar muito para cada pessoa, e tais variações dificultam a análise. Além do estilo de escrita, existem outros fatores que podem aumentar a complexidade da tarefa: podemos ter imagens de números escritos com lápis, ou caneta, caracteres podem ter tamanhos distintos, etc. No entanto, sabemos que existe um padrão para cada algarismo, senão as pessoas não conseguiriam trocar informações. É este padrão que queremos aprender a identificar neste exemplo (Hastie08).

\section{0}

Figura 2.1: Exemplo de escrita manual digitalizada

Este é um problema de OCR (Optical Character Recognition) (Alpaydin04) e sua solução pode ser usada, por exemplo, como módulo de reconhecimento de códigos postais, pertencente a sistema de endereçamento automático de correspondências dos Correios. Este desafio, faz parte do repertório de problemas que podem ser resolvidos com Aprendizado de Máquina, mais precisamente, usando as técnicas de classificação, mencionadas nas seções subsequentes. De fato, considere 10 classes, uma para cada algarismo. O objetivo deste problema é identificar, com base em um conjunto de pontos extraído de um pedaço de uma imagem nunca vista até então, o algarismo que melhor representa a parte analisada.

Além do reconhecimento de escrita manual já citado, existem muitas outras aplicações para o Aprendizado de Máquina, incluindo previsão da variação dos preços de ativos nas bolsas de valores, filtro anti-spam, auxílio no diagnóstico de doenças e resultado de exames médicos, detecção de fraudes, re- 
conhecimento de impressões digitais, da íris, ou de voz (Alpaydin04), predição do risco de crédito (Credit Scoring) (Hand98), etc.

\section{2}

\section{Aprendizado Supervisionado}

O problema de classificação, visto como exemplo no início deste capítulo pode ser considerado um problema de Aprendizado Supervisionado, uma vez que temos um domínio de resposta bem definido com 10 possíveis classes (uma para cada algarismo) (Hastie08).

Neste tipo de exemplo, recebemos uma entrada contendo um conjunto de dados históricos - também chamado de corpus, corpora, dataset, ou experiência de treinamento (Mitchell97), e para cada instância deste conjunto, temos a classe correta já mapeada. A partir destes dados, treinamos algoritmos de aprendizado supervisionado para aprenderem as regras de associação e os padrões que levam cada instância à sua classe.

Após a etapa de treinamento, existe a fase de validação, que é onde calculamos a taxa de sucesso obtido pelo modelo proposto. O processo de melhora da acurácia é geralmente árduo, pois exige a repetição das etapas de alteração do modelo, treinamento e validação inúmeras vezes, até alcançarmos resultados satisfatórios para a tarefa escolhida.

Explicamos os processos de aprendizado supervisionado com mais detalhes no capítulo 3 .

\section{3}

\section{Aprendizado Não-supervisionado}

Enquanto no problema de OCR, elaborado para introduzir os fundamentos básicos do capítulo, temos a quantidade de classes pre-definida, nos problemas de Aprendizado Não-supervisionado, não possuímos à priori o mapeamento entre as instâncias e as classes (Alpaydin04).

Uma forma de organizarmos nosso dataset quando não temos as classes bem definidas é utilizando uma técnica de Aprendizado Não-supervisionado, chamada de Clusterização, ou Clustering. Neste método, o objetivo é, através da análise dos dados, estabelecer a existência de clusters, ou agrupamentos, empregando uma função para calcular a similaridade entre cada instância (Michie94).

Assim como a Classificação é um método de Aprendizado Supervisionado, a Clusterização é um método de Aprendizado Não-Supervisionado. 
Nosso foco principal não é nos métodos de Aprendizado Nãosupervisionado, entretanto, planejamos, futuramente, expandir o trabalho realizado para englobar novos métodos de Aprendizado de Máquina.

\section{4}

\section{Engenharia de Atributos}

Deixemos o problema de OCR de lado, e retomemos o foco para o assunto do estudo de caso abordado no capítulo 5: classificação de produtos.

Segundo (Thor), podemos considerar o problema de classificação de produtos como um problema de particionamento. Dado um conjunto de ofertas de produtos $O=\left\{o_{1}, o_{2}, \ldots, o_{n}\right\}$, o resultado do processo de classificação é o particionamento de $\mathrm{O}$, isto é, um conjunto de partições sem sobreposição $P=\left\{p_{1}, p_{2}, \ldots, p_{k}\right\}$ onde $p_{i} \cap p_{j}=\emptyset$, para $1 \leq i \leq j \leq k$ e $p_{1} \cup p_{2} \cup \ldots \cup p_{k}=O$. O objetivo é que todas as ofertas $o_{i}$ da partição $p_{j}$ representem o mesmo produto do mundo real e que todas as demais ofertas se referenciem a produtos diferentes.

Para cada instância $o_{i}$, temos vinculados alguns atributos, tais como a descrição e a categoria. No entanto, nenhum dos algoritmos utilizados aceitam texto como entrada, deste modo, precisamos converter as descrições de ofertas numa estrutura denominada de saco de palavras (bag of words (Maron61) e (Lewis98)) e criar uma representação vetorial para cada $o_{i}$, como na tabela 2.1 .

Esta é a abordagem mais trivial para o problema, e consiste em gerar um dicionário $\mathbf{W}$ contendo todas as palavras que fazem parte de cada elemento de $\mathbf{X}$, o que nos permite atribuir um número único para cada palavra do dicionário - através da sua posição no dicionário. Em seguida, basta contarmos o número de vezes que cada palavra $w_{j}$ aparece para cada elemento $o_{i}$. Para a seguinte entrada, por exemplo:

$o_{1}=$ "MONITOR LCD 19 ACER X193W WIDE PRETO"
$o_{2}=$ "MONITOR LCD ACER X193W ABD 19 20000:1"

É criado o dicionário abaixo:

$W=\{$ MONIT, LCD, 19, ACER , X193W, WIDE , PRETO , ABD , $20000: 1\}$

Após a construção da representação vetorial, obtemos a matriz a seguir:

Através da representação vetorial das palavras é possível computar distâncias, similaridade e outras estatísticas (Smola08). 
A técnica descrita acima é apenas um dos artifícios utilizados para realizar a Engenharia de Atributos, durante a fase de modelagem da solução proposta. Na seção 3.5 descrevemos outras técnicas disponíveis para pré-processar as instâncias e no capítulo 5 explicamos algumas abordagens empregadas para tratar o problema elaborado no estudo de caso.

\section{5}

\section{Seleção de Atributos}

Conforme a quantidade de atributos cresce - e o modelo vai se tornando mais elaborado, o processo de treino e validação pode se tornar mais demorado para alguns classificadores, já que a complexidade dos algoritmos, eventualmente, está relacionada com o total de atributos analisados. No entanto, nem todos os atributos trazem informações relevantes para a classificação. Identificar os atributos que oferecem maior Ganho de Informação (Quinlan93) para a solução e descartar aqueles que reduzem a acurácia faz parte de um processo chamado de Seleção de Atributos, e pode ser empregado para melhorar a eficiência da solução.

Existem diversas técnicas para a Seleção de Atributos tais como Proportional Difference (Simeon08), Fisher Kernel (Jaakkola98), etc.

\section{6}

\section{Trabalhos Relacionados}

Em 1993 a Universidade de Waikato, na Nova Zelândia começou o desenvolvimento do WEKA (Waikato Environment for Knowledge Analysis). O WEKA, além da sua API de desenvolvimento escrita em Java, também possui um conjunto de interfaces gráficas que possibilita sua utilização de uma forma simplificada, mesmo sem nenhum conhecimento em desenvolvimento de aplicações. Por isto, o WEKA foi intitulado como Ambiente de Analise de Conhecimento já que desempenha tarefas muito além de um framework. Em função da sua facilidade de uso, o WEKA ganhou notoriedade na área de Aprendizado de Máquina e é amplamente utilizado acadêmica e comercialmente.

O WEKA disponibiliza cinco modos diferentes de interação:

\begin{tabular}{l|llllllll} 
W & MONITOR & LCD & 19 & ACER & X193W & WIDE & ABD & $20000: 1$ \\
\hline$o_{1}$ & 1 & 1 & 1 & 1 & 1 & 1 & 0 & 0 \\
$o_{2}$ & 1 & 1 & 1 & 1 & 1 & 0 & 1 & 1
\end{tabular}

Tabela 2.1: Representação vetorial das palavras 
Interface Gráfica: Explorer Através desta interface, é possível escolher um dataset, aplicá-lo um conjunto de filtros, e executar os algoritmos de classificação, agrupamento ou associação sobre as suas instâncias.

Interface Gráfica: KnowledgeFlow Permite realizar as mesmas operações descritas acima, mas fornece uma interface intuitiva, onde é possível desenhar um fluxo de execução mais complexo (workflow), através de elementos gráficos.

Interface Gráfica: Experimenter Simplifica a execução de vários experimentos utilizando datasets diferentes em cima de uma mesma configuração.

Simple CLI Console para executar comandos do WEKA.

Programaticamente O WEKA fornece uma vasta API que nos permite desenvolver aplicações utilizando-se de todos os seus recursos.

Apesar da grande variedade de meios de interagir com o WEKA, o desenvolvedor que está construindo aplicações sobre sua API possui poucas ferramentas para ajudá-lo nesta tarefa, e nenhuma das interfaces gráficas disponibilizadas no ambiente do WEKA possuem o propósito de apoiarem esta atividade. E é neste ponto que o EasyLearn é útil, provendo uma camada de configuração de simples entendimento e facilmente reaproveitável. A proposta do EasyLearn é semelhante ao conceito da interface KnowlegdeFlow - onde é possível definir um workflow que será usado para guiar a execução do WEKA, no entanto, seu foco é integração entre aplicação, e não é baseada em elementos visuais mas em arquivos XML com um padrão bem definido.

O EasyLearn foi construído sobre o WEKA, conforme explicamos no capítulo 4, contudo, prevemos como trabalho futuro (capítulo 6) modificar sua arquitetura para deixá-lo capaz de suportar outros frameworks de Aprendizado de Máquina, como o Apache Mahout, Encog Machine Learning Framework, GraphLab, RapidMiner, etc. 


\section{Processos de Aprendizado Supervisionado}

Dedicamos um capítulo para dissecar os processos de Aprendizado Supervisionado, mais precisamente, aqueles que tratam o problema da Classificação (seção 2.1). Os processos descritos aqui foram utilizados como base para o desenvolvimento do framework proposto. No entanto, o framework foi implementado para suportar variações nestes fluxos - como o procedimento descrito em (Kotsiantis07), sem que haja necessidade de mudanças no código-fonte. Além disto, novos processos podem ser definidos e implementados sem necessitar de conhecimentos avançados de programação.

Para facilitar o entendimento desenhamos cada processo descrito neste capítulo utilizando a notação BPMN (Business Process Modeling Notation).

\section{1}

\section{Pre-requisitos}

Todos os processos de Aprendizado Supervisionado descritos abaixo, têm como pre-requisito a construção de um Corpus. A etapa da construção do Corpus pode ser vista em detalhe no capítulo 5.2, onde explicamos como construímos o Corpus utilizado no estudo de caso de Classificação de Produtos do comércio eletrônico.

\section{2}

\section{Avaliação}

O primeiro processo é o de Avaliação (figura 3.1). Normalmente este processo é o mais dispendioso em relação ao tempo e ao esforço investido, pois, muitas vezes, são necessárias inúmeras execuções deste processo, até que seja alcançado uma acurácia satisfatória. A cada execução diversos parâmetros precisam ser calibrados até que tudo esteja pronto para o processo seguinte: aprendizado (seção 3.3).

Extrair/Filtrar Corpus Uma vez que o Corpus tenha sido criado, o primeiro passo é transformá-lo em um DataSource (já utilizando a nomenclatura do EasyLearn). Um DataSource é um arquivo de entrada de dados, independente do formato, que pode conter todo o Corpus ou um subconjunto 
dele. No estudo de caso, apresentado no capítulo 5, dividimos o nosso Corpus em vários DataSources: um para cada categoria.

Processar dados Normalmente é necessário um processamento à priori do DataSource, isto é, um pré-processamento. Esta etapa de preparação dos dados possui um papel fundamental para a qualidade dos resultados obtidos ao final do processo de avaliação, pois é onde aplicamos uma série de técnicas de padronização, simplificação e correção da entada a ser processada. Na seção 3.5 exemplificamos e descrevemos alguns artifícios utilizados nesta etapa.

Realizar / Aperfeiçoar Engenharia de Atributos O passo subsequente ao pré-processamento é criar um modelo de atributos baseado no domínio do problema em questão, afinal, nem sempre o DataSource irá conter todos os atributos necessários para capturar os detalhes do problema a ser solucionado. Neste caso, é necessário identificar e extrair atributos ocultos do modelo inicial através da análise de atributos mais primitivos (Markovitch02). Para ajudar nesta etapa o EasyLearn provê alguns recursos para extração de atributos (capítulo 4). Assim como, eventualmente, é necessário criar novos atributos para enriquecer o modelo, algumas vezes precisaremos restringir a quantidade de atributos removendo atributos redundantes e irrelevantes para melhorar a eficiência dos classificadores (Yu2004). Para a seleção de atributos, o Weka fornece diversos Seletores que foram encapsulados no EasyLearn.

Separar DataSource Caso não tenhamos disponível um DataSource de Publicação, isto é, um DataSource construído especialmente para realização de testes para avaliação do modelo a ser criado, precisamos dividir o DataSource em dois conjuntos, um para o treinamento e outro para a avaliação. As técnicas de avaliação são descritas mais detalhadamente logo abaixo, no processo Avaliar Modelos.

Escolher e Treinar Classificadores Infelizmente, não existe um classificador que atenda a todos os propósitos. Cada classificador, normalmente, possui as suas vantagens e desvantagens. Alguns classificadores não suportam atributos textuais, ou atributos com valores nulos, outros classificadores podem não apresentar um desempenho satisfatório para um determinado DataSource. Enfim, existe uma grande variedade de Classificadores disponíveis, e um passo importante é escolher bem o conjunto dos classificadores elegíveis para solucionar o problema em questão. O EasyLearn tem um papel importante neste momento, pois torna possível 
avaliar uma série de classificadores em uma única execução do fluxo. Desta forma, não é necessário executar todos os passos anteriores a este para cada classificador, isto possibilita uma economia de tempo do desenvolvedor, melhorando a eficiência da execução do processo de Avaliação. Uma vez que o conjunto de classificadores é definido, cada classificador precisa ser treinado com a parte do DataSource separada anteriormente para o aprendizado.

Avaliar Modelos Este processo é executado para cada classificador a ser avaliado e recebe como entrada dois artefatos: o classificador já treinado e o DataSource de avaliação. Existem basicamente três técnicas para medir a acurácia do modelo produzido ao final do processo de classificação. A primeira consiste em dividir o DataSource inicial em duas partes: uma parte usada no treinamento do classificador - contendo dois terços das instâncias, e a outra parte utilizada para avaliar o classificador treinado - contendo o restante das instâncias. A segunda técnica, conhecida como Validação Cruzada, consiste em dividir o DataSource em algumas partes mutualmente exclusivas e de igual tamanho, e para cada parte, o classificador é treinado utilizando a união de todas as demais partes, e avaliado utilizando as instâncias que não pertencem ao conjunto de instâncias usadas no treinamento (explicaremos melhor esta técnica aplicada ao Estudo de Caso, na seção 5.2.3). A precisão é calculada baseada na média de erro da classificação para cada subparte. Este método é computacionalmente mais custoso, no entanto, é normalmente utilizado quando precisamos ter uma medida mais precisa da acurácia (Kotsiantis07). Por fim, a terceira técnica não exige que o DataSource inicial seja dividido automaticamente, pois conta com um outro DataSource (DataSource de publicação ou de teste) construído manualmente para testar o modelo gerado. Normalmente a construção deste conjunto de Publicação requer muito esforço, e nem sempre a aplicação desta técnica é viável para o problema, por isto, as outras duas técnicas são mais utilizadas no cotidiano (Alpaydin04).

Identificar Inconsistências do corpus Até que o Corpus esteja suficientemente consistente para ser utilizado com segurança, é natural que ele passe por uma série de revisões e atualizações. Normalmente, este é um processo manual, e é uma etapa importante para melhorar a qualidade da solução.

Atualizar Corpus Cada inconsistência percebida na etapa anterior precisa ser corrigida no Corpus. Este passo normalmente acontece por fora do 
EasyLearn, no entanto, caso haja necessidade, é possível modificar o framework para suportar tarefas como esta. Após atualizar o Corpus, o processo de avaliação deve ser reiniciado.

Salvar Relatórios de Execução Ao final de cada execução do processo de avaliação, o framework deve gerar um relatório, informando, para cada classificador, sua acurácia, o tempo gasto para treinar e o tempo gasto para avaliar todas as instâncias. Além disto, é importante que este relatório contenha informações que indiquem quais foram os parâmetros utilizados naquela execução. Utilizando o EasyLearn é possível configurar outros relatórios, além de definir se tais estatísticas devem ou não ser armazenadas para futuras referências.

\section{3}

\section{Aprendizado}

Uma vez que o processo de Avaliação tenha sido concluído, entra em cena o processo de Aprendizado (figura 3.2), que é quando preparamos e treinamos os classificadores escolhidos anteriormente para serem utilizados com dados reais.

Abrir DataSource O primeiro passo é carregar o DataSource que será utilizado para treinar os classificadores. Neste caso, podemos utilizar todas as instâncias do DataSource, já que não haverá etapa de avaliação. $\mathrm{Na}$ maioria das vezes, isto ajuda a melhorar a qualidade da solução. No entanto, a ideia de que quanto mais instâncias, melhor a qualidade, nem sempre é uma verdade no processo de Classificação, inclusive, em alguns casos é necessário reduzir a quantidade de instâncias, seja por questões de desempenho, ou até mesmo, por prejudicar a acurácia gerando ruído no Corpus. Então, fica a critério do usuário da API escolher se deverá ou não utilizar todo o DataSource no treinamento ou apenas a parte utilizada no processo de Avaliação.

Preprocessar dados Esta etapa de pré-processamento é a mesma etapa do processo de Avaliação. Para evitar que o usuário tenha que duplicar a definição utilizada para configurar o processo de Avaliação, o EasyLearn possui uma forma de simplificar os arquivos de configuração, evitando duplicação do código. Este artifício é explicado melhor no capítulo 4.

Realizar Engenharia de Atributos Assim como na etapa de préprocessamento, esta etapa também já foi definida no processo de Avaliação e deve ser reaproveitada neste momento. 
Treinar Classificadores Cada classificador utilizado deve ser treinado com o DataSource que foi carregado no primeiro passo deste processo.

Serializar e persistir Modelos Ao final do treinamento, cada classificador é serializado e persistido para ser utilizado no processo seguinte (seção 3.4). A forma que o EasyLearn persiste os classificadores pode ser redefinida. Atualmente, o framework apenas serializa e comprime cada classificador utilizando Deflate ou ZIP, mas poderíamos salvar os classificadores criptografados, caso haja a necessidade.

\section{4}

\section{Classificação}

O processo de Classificação (figura 3.3) é o ultimo processo do ciclo de Aprendizado Supervisionado por Classificação. Caso, ao final deste ciclo, os resultados não sejam satisfatórios, é necessário voltar à primeira etapa e reajustar cada parâmetro da execução. Este processo ilustra como, enfim, a solução gerada é utilizada em um contexto real.

Extrair Dados Reais Esta é a etapa de carga do DataSource contendo os dados reais a serem classificados.

Preprocessar dados O DataSource contendo os dados reais, então, deve ser pré-processados da mesma forma que os DataSources de treinamento e avaliação foram processados nos processos anteriores, caso este cuidado não seja tomado podemos resultar em um DataSource incompatível com o modelo persistido no processo de Aprendizado.

Carregar Modelo Serializado O modelo treinado e serializado no processo de Aprendizado deve ser carregado em memória.

Classificar DataSource O DataSource contendo os dados reais é classificado pelo modelo carregado no passo anterior.

Processar DataSource Classificado O resultado da classificação é então pós-processado. Esta etapa é um HotSpot do framework concebido, e deve ser implementada pelo usuário da API. Normalmente esta fase consiste em salvar as instâncias classificadas em um sistema legado, ou em um arquivo tabulado. Também pode ser interessante classificar cada instância de acordo com a certeza do classificador, permitindo assim, que instâncias que possuem um grau baixo de certeza em sua classificação possam ser revisadas manualmente ao final do processo de Classificação. 


\section{5}

\section{Procedimentos de Pré-processamento}

Mencionamos abaixo as técnicas mais corriqueiras de Processamento de Linguagem Natural, Mineração de Texto, Recuperação de Informação (Information Retrieval) e Aprendizado de Máquina que suportam a etapa de pré-processamento do DataSource. Parte desta seção foi baseada no livro de (Indurkhya10) que dedica um capítulo inteiro para explicar os desafios do preprocessamento textual.

Encoding Em domínios de problemas que envolvem textos em diversas línguas, por exemplo, configurar e padronizar o Encoding do DataSource pode ser um desafio, mas é um dos primeiros, senão o primeiro passo, antes de aplicar qualquer outro filtro de pré-processamento.

Normalização Este é um conceito amplo, e, neste caso, estamos nos referindo à todas as formas de normalização possíveis. Normalização textual: processamento das "non-standard words" (NSW), tais como endereços de e-mail, URL, abreviações, valores monetários, datas (Sproat01), espaços em branco, caracteres especiais e palavras com diferenças na capitalização (WinNT, LaTeX) (Manning99), hifenização, etc...; Normalização Unicode: procedimento responsável por substituir sequências de caracteres compostos (letras acentuadas, cedilha, etc..) - que podem possuir diversas representações possíveis, dependendo da codificação, em uma única sequência, evitando que o mesmo carácter composto seja representado de várias formas (Unicode11).

Stemming Stemming é uma forma de normalização e consiste no processo de reduzir uma palavra ao seu radical, removendo os seus afixos (Manning99). Por exemplo:

\section{Stemming ('pedrada') $=$ Stemming ('pedrinha') $=$ 'pedr'.}

Através do Stemming é possível reduzir a quantidade de atributos do modelo gerado, uma vez que várias palavras que compartilham o mesmo radical serão substituídas pelo seu radical comum. Esta técnica é útil para melhorar a eficácia dos algoritmos de busca textual e é amplamente utilizada na área de Processamento de Linguagem Natural.

Verificação Ortográfica (Spellchecking) Estimativas indicam que a frequência dos erros de digitação variam entre $0.05 \%$ em matérias jornalísticas revisadas, até $38 \%$ para aplicações complexas, como busca em um catálogo telefônico, por exemplo (Kukich92). 
Para mitigar este erro e evitar que ele cause distorções nos resultados, é recomendado, na maioria das tarefas de Processamento de Linguagem Natural, aplicar uma verificação ortográfica antes de iniciar o processamento.

No trabalho de (Kukich92) e nos livros de (Indurkhya10) e (Teller00) podemos conferir em detalhes as técnicas mais utilizadas para correção ortográfica, tais como Distância Mínima de Edição, técnicas de análise de $N$-grams, técnicas probabilísticas ou baseadas em regras, etc..

Substituição de Sinônimos Dependendo do problema a ser resolvido, pode ser relevante substituir palavras ou sentenças com o mesmo significado por seus sinônimos a fim de reduzir o vocabulário a ser tratado. Para sinônimos da língua inglesa, esta tarefa pode ser apoiada com o uso do WordNet - que é um grande banco de dados léxico do Inglês. No WordNet, substantivos, verbos, adjetivos e advérbios são agrupados em conjuntos de sinônimos cognitivos (synsets), cada um expressando um conceito distinto. Os synsets estão interligados por meio de relações semânticas (Fellbaum98).

Segmentação O processo de segmentação pode se referir a palavras ou sentenças em um documento textual. A segmentação de palavras visa quebrar uma sequência de caracteres de acordo com o limite de cada palavra. Cada palavra identificada é chamada de token, e este procedimento também é conhecido como Tokenização. Na maioria das linguagens este processo funciona baseado em espaços em branco que comumente são utilizados para separar as palavras, contudo, em algumas línguas/dialetos especialmente as dos países do leste asiático (chinês, japonês, tailandês), o processo de segmentação de palavras pode ser bem desafiador, já que, neste caso, não é possível realizar a separação das palavras por espaços em branco exigindo abordagens mais sofisticadas (Manning99).

Eliminação de Stopwords As stopwords são termos frequentes em uma linguagem e, geralmente, não são representativos no contexto do documento analisado. Esta lista é constituída por artigos, advérbios, números, pontuação, preposições e pronomes.

Exemplos de stopwords da língua portuguesa : a, alguma, após, com, de, e, é, ela, ele, em, o, os, ou, pela, porque, tem, um, uma, entre outras. A remoção das stopwords pode oferecer um ganho de desempenho para os algoritmos de classificação, dependendo do caso. 
Seleção de Atributos A seleção de atributos é apresentada na seção 2.5 e foi mencionada nesta lista para ressaltar que se trata de uma técnica executada à priori.

Seleção de Instâncias A habilidade de analisar e interpretar grandes conjuntos de dados está muito aquém da capacidade de armazenamento atual. Para confrontar este desafio, as áreas de Descoberta de Conhecimento e Mineração de Dados precisam estar em constante evolução para permitir lidar com datasets cada vez maiores. O tópico de Seleção de Instâncias compreende uma série de técnicas, tais como detecção de inconsistências no corpus (como visto no próximo item Detecção de ruídos) e redução da quantidade de instâncias do corpus - através de métodos de otimização, onde buscamos minimizar a quantidade de instâncias e maximizar a precisão (Motoda01). Um exemplo real de seleção de instâncias é o caso de reconhecimento de escrita manual - ilustrado logo na apresentação dos conceitos básicos de Classificação (seção 2.1), onde precisamos classificar um conjunto de coordenadas cartesianas em um algarismo de zero à nove. Dependendo da forma que estas coordenadas tenham sido capturadas (por sensores ou através de dispositivos sensíveis ao toque, por exemplo) é normal que haja uma distância muito pequena entre duas coordenadas (de acordo com a frequência de leitura dos sensores), resultando na leitura de um número de coordenadas muitas vezes maior do que a quantidade necessária para a classificação. Caso esta quantidade exagerada de coordenadas esteja impactando no desempenho da classificação recomenda-se realizar uma suavização dos dados, isto é, a seleção de pontos chaves da imagem capturada (conjunto de coordenadas). Desta forma, a tendência é reduzir a quantidade de ruídos e fenômenos pontuais ou momentâneos do DataSource.

Detecção de ruído (outlier) Esta técnica possui diversas denominações na literatura: detecção de anomalias, detecção de inconsistências, deteç̧ão de desvio, mineração de exceções, etc. (Hodge04). De acordo com (Barnett94), um outlier pode ser definido como:

Uma observação (ou subconjunto de observações) que parece ser inconsistente em relação ao restante do conjunto de dados.

Como estamos na seção de pré-processamento, nos referimos neste item à detecção de ruídos como ferramenta de processamento à priori, uma vez que o termo de detecção de outliers também é utilizado para se referir a uma gama de problemas de classificação, por exemplo, à sis- 
temas de detecção de intrusão (através de análise de arquivos de log a procura de atividades suspeitas), ou sistemas de detecção de fraudes (através da análise de uma série de operações de cartão de crédito). No nosso contexto, estamos analisando a detecção de outliers como artifício para melhorar a qualidade do conjunto de dados - eliminando as inconsistências e minimizando possíveis interferências nos resultados do processo de classificação. Existem basicamente três formas de realizar este procedimento. Duas delas utilizam métodos de Aprendizado Supervisionado, isto é, pode demandar um grande esforço de preparação de um segundo corpus indicando e classificando manualmente o que é um outlier - tarefa que, dependendo do caso, provavelmente não compense o tempo investido em relação ao benefício gerado, no entanto, também é possível cumprir este propósito utilizando aprendizado não-supervisionado, mais especificamente, com técnicas de Agrupamento (clustering). Este último artifício possui um custo muito menor em relação aos métodos de aprendizado supervisionado. Para se aprofundar mais neste assunto, recomendamos a leitura do trabalho A Survey of Outlier Detection Methodologies (Hodge04).

Instâncias Sintéticas Ao passo que eventualmente precisamos reduzir o tamanho do nosso conjunto de dados - como visto no item Seleção de Instâncias, em alguns casos, é necessário que instâncias produzidas artificialmente sejam introduzidas no corpus. Isto pode ser necessário quando estamos trabalhando com datasets desbalanceados, ou seja, quando existe uma discrepância alta em relação à distribuição de frequência das classes presentes no dataset analisado. Datasets com esta características podem interferir negativamente no processo de classificação, podendo produzir palpites tendenciosos para as classes que possuem uma representatividade maior. Com o objetivo de atingir uma distribuição mais igualitária de frequências das instâncias para classes, em (Kegelmeyer02), é apresentado uma técnica que visa produzir instâncias sintéticas para as classes com menor representatividade, enquanto, elimina algumas instâncias das classes que possuem maior distribuição.

Um exemplo de contexto onde o uso desta técnica é recomendado é na análise de mamografias para a detecção automática de tumores. Em um dataset de mamografias, em torno de $98 \%$ dos exames são normais, enquanto apenas $2 \%$ das mamografias contém anomalias. Uma estratégia convencional de classificação, deve produzir uma acurácia próxima aos 98\%, mas não garante uma taxa de acerto elevada para a classe minoritária. A natureza desta aplicação requer uma taxa de erro elevada 
para os exames contendo anomalias, enquanto permite uma taxa de erro pequena na predição da classe majoritária - onde não há anomalias (Woods93).

Atributos ausentes (Missing Features) Muitos algoritmos de classificação não suportam atributos com valores ausentes. Ao utilizar estes classificadores, precisamos ter o cuidado de tratar os atributos sem valores no nosso dataset substituindo-os, sempre que possível, por valores plausíveis - este procedimento é chamado de imputação. Caso este tratamento não seja feito cuidadosamente, podemos afetar nossos classificadores deixando-os mais inclinados à realização de predições erradas. Para se aprofundar neste assunto, encontramos uma análise de quatro procedimentos para tratar atributos ausentes em (Batista03) . 


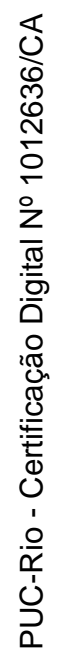

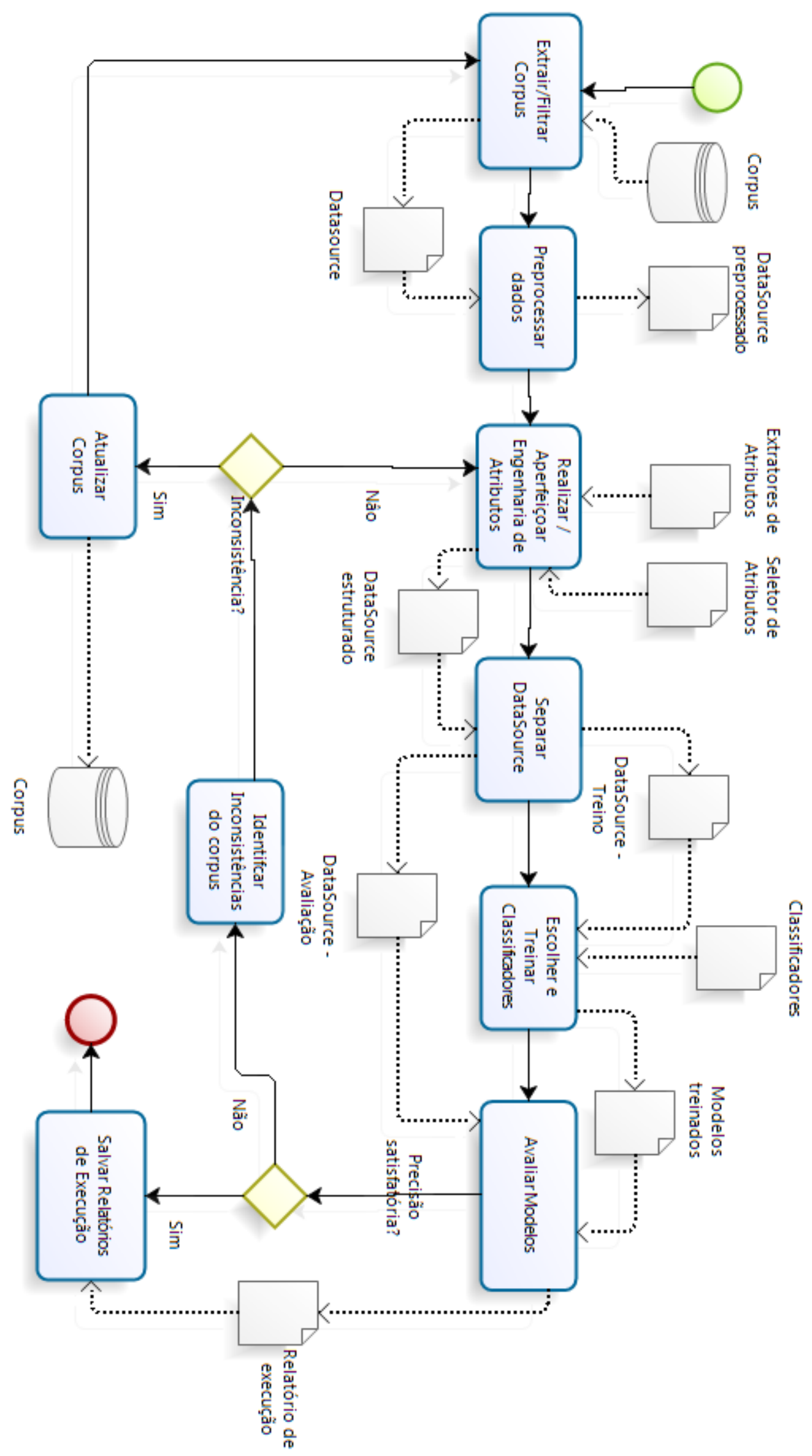

Figura 3.1: Processo de avaliação 


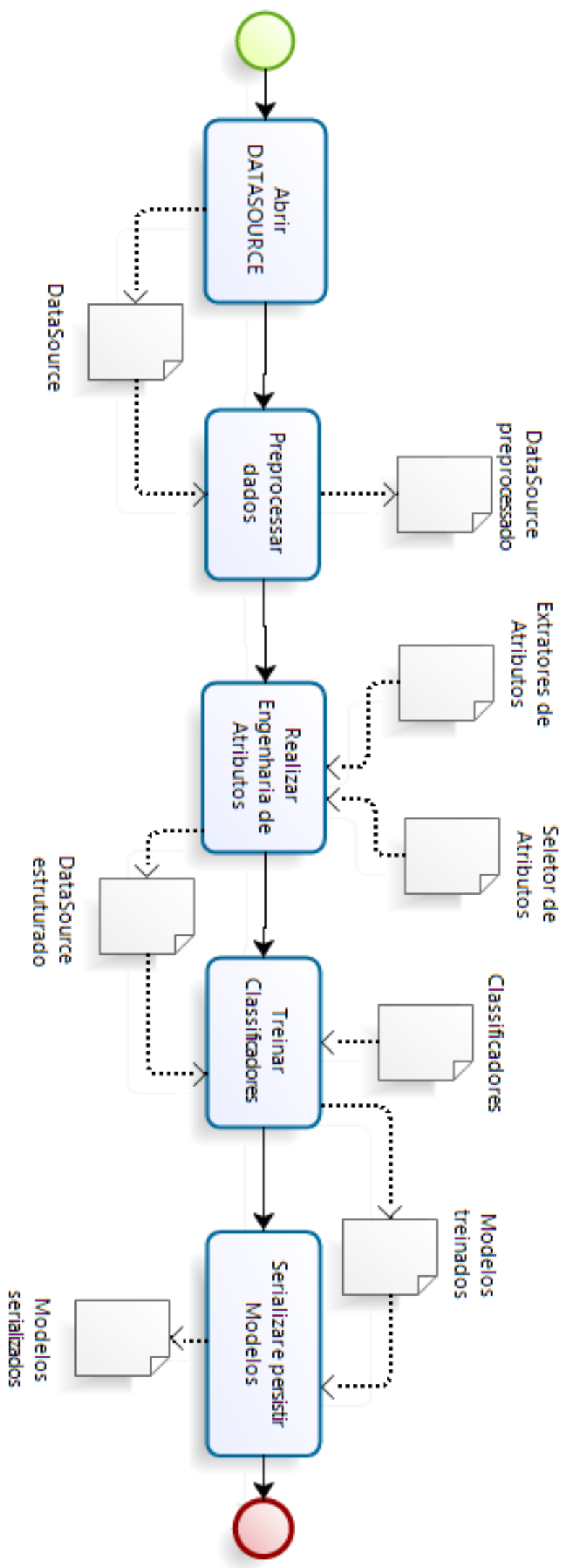

Figura 3.2: Processo de aprendizado 


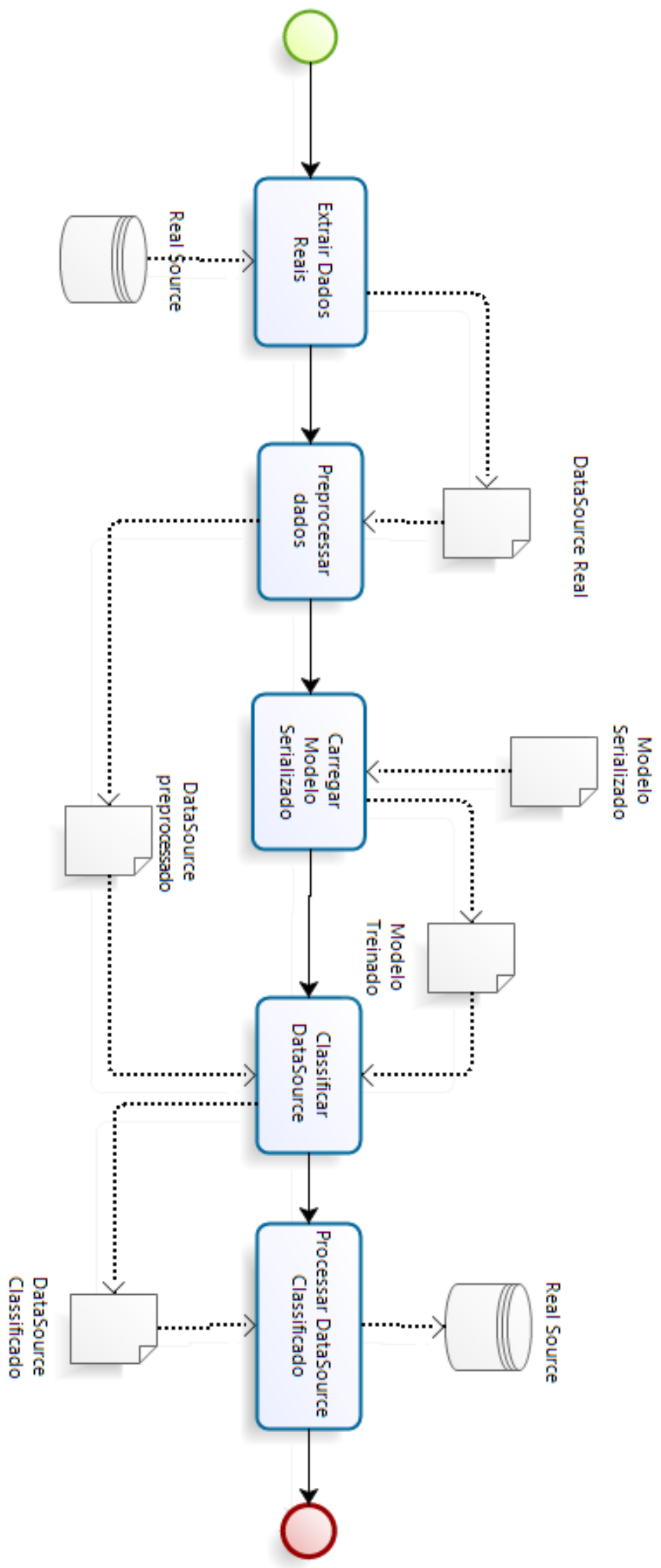

Figura 3.3: Processo de classificação 


\section{Arquitetura}

A arquitetura apresentada neste capítulo foi definida para cumprir os requisitos enumerados abaixo (seção 4.1). O EasyLearn se apoia sobre o framework WEKA da Universidade de Waikato, criando uma camada intermediaria para o desenvolvedor de aplicações para classificação de entidades, como é ilustrado pela figura 4.1.

Todos os classificadores e filtros implementados pelo WEKA podem ser facilmente encapsulados para serem utilizados pelo EasyLearn.

O EasyLearn recebe como entrada um conjunto de arquivos de configuração no formato XML, além do DataSource a ser processado. Sua saída é customizável, e pode ser configurada para produzir, por exemplo, relatórios de acurácia da classificação, o próprio DataSource classificado, ou o modelo de classificação já treinado.

\section{1}

\section{Requisitos}

Relacionamos os seguintes requisitos para pautar o desenvolvimento do EasyLearn:

- Simples entendimento, manutenção e configuração.

- Comportar os processos de Avaliação, Aprendizado e Classificação descritos no capítulo 3 e suas possíveis variações.

- Suportar um fluxo genérico de execução, atendendo a qualquer problema relacionado ao Aprendizado Supervisionado utilizando Classificação.

- Suportar e combinar vários seletores e classificadores em uma mesma execução.

- Suportar qualquer tipo de entrada de dados (JDBC, ARFF, CSV ...).

- Ser facilmente integrável com sistemas legados.

- Produzir relatórios de execução por rodada.

- Armazenar organizadamente os modelos produzidos, salvando o estado de cada classificador após o treinamento, para tornar os processo de avaliação e classificação mais eficientes. 
- Prover um repertório dos principais artifícios de mineração de texto, processamento de linguagem natural e outros recursos comuns à maioria dos problemas relacionados.

- Utilizar o framework WEKA como motor de Aprendizado de Máquina de forma transparente para o usuário da $A P I$.

\section{2}

\section{Conceitos}

Definimos os conceitos de Base de Conhecimento (KnowledgeBase) e de Fluxo de Conhecimento (KnowlegeFlow) para apoiar a implementação do framework, ambos os conceitos são explicados nas seções seguintes.

\subsection{1}

\section{Knowledge Base}

A ideia por trás da KnowledgeBase é fornecer um espaço de trabalho (workspace) para o EasyLearn. A Base de Conhecimento é onde ficam armazenados os relatórios de execução do framework (knowledgeBase/reports), dicionários utilizados pelos extratores de atributos (knowledgeBase/libary), os modelos serializados (knowledgeBase/classifier), os DataSources utilizados - quando os dados não vêm diretamente do Banco de Dados (knowledgeBase/source) e, por fim, os fluxos de conhecimento descritos na seção 4.2.2 (raiz da knowledgeBase).

\subsection{2}

\section{Knowledge Flow}

O fluxo de conhecimento é definido por um arquivo de configuração que determina a sequência de execução do EasyLearn. Este conceito sustenta o requisito de flexibilidade do framework. Através da criação de um fluxo de conhecimento é possível estabelecer de uma forma mais amigável os processos definidos no capítulo 3. Além disto, o EasyLearn permite criar uma hierarquia entre os fluxos de conhecimento de uma forma semelhante às linguagens orientadas à objeto, implementando os conceitos de herança e polimorfismo, maximizando o reuso dos arquivos de configuração para problemas mais complexos - estas propriedades são explicadas em detalhes na seção 4.4. 


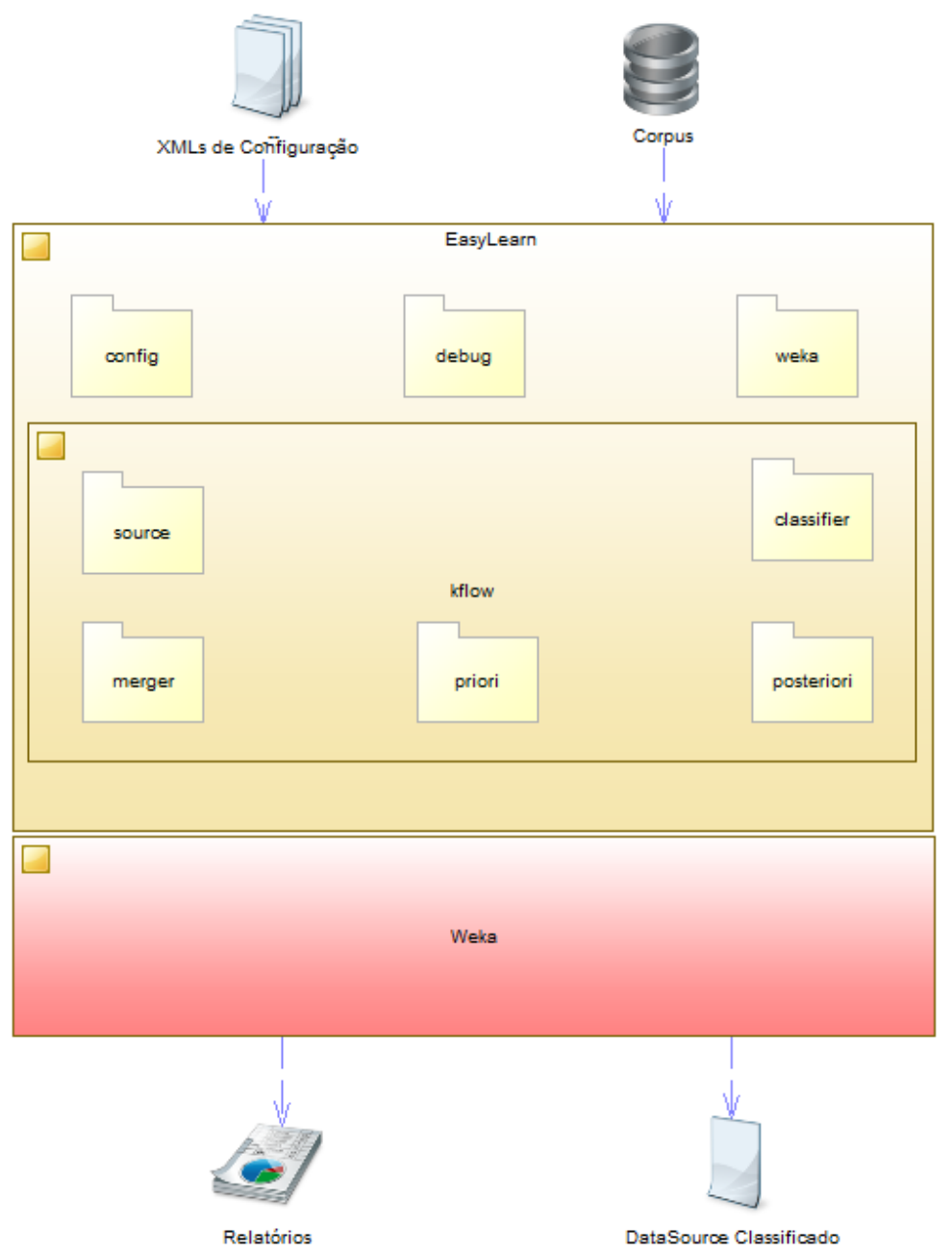

Figura 4.1: Visão geral da Arquitetura do framework

\section{3}

\section{Pacotes e Classes do EasyLearn}

No anexo A descrevemos cada pacote visto na figura 4.1 juntamente com as suas classes, detalhadamente. Estes elementos constituem a base do framework EasyLearn

\section{4}

\section{Configuração}

Uma das principais premissas por trás do EasyLearn é simplificar o desenvolvimento de projetos de classificação de entidades, no entanto, cada solução proposta para cada problema pode possuir inúmeras possibilidades de customização e parametrização. Para manter a simplicidade do framework e, ainda assim, atingir todos os requisitos de flexibilidade da solução, criamos duas formas de configuração da infra-estrutura proposta:

- Programaticamente (objetos do pacote Matcher.Config) 
- XML de configuração

Explicamos os objetos do pacote Matcher.Config na seção A.2. A seção atual foi dedicada para ver com mais detalhes a estrutura do XML de configuração - que é o coração do framework.

Na figura 4.2 podemos ver o diagrama do esquema de definição do XML de configuração utilizado pelo EasyLearn (XSD). Após o processamento do arquivo de configuração, cada elemento do XML é transformado em objetos do pacote Matcher. Config. Sendo assim, é possível identificar de forma clara a relação de cada bloco interno do XML com as classes explicadas na seção A.2.

A principal ideia pro trás do conceito de KnowledgeFlow (seção 4.2.2) é permitir o mapeamento de cada um dos processos descritos no capítulo 3. Desta forma, cada XML contém a configuração de um KnowledgeFlow, que, por sua vez, representa um processo de aprendizado supervisionado. Contudo, se analisarmos com atenção os processos estudados no capítulo 3, podemos perceber que estes processos possuem algumas interseções em seus fluxos (como por exemplo a atividade Pré-processar dados). Caso não nos atentássemos a estas operações comuns entre os processos de aprendizado supervisionado, introduziríamos um problema para manter os arquivos de configuração, uma vez que, qualquer modificação em um KnowledgeFlow poderia afetar e repercutir em vários outros arquivos - denegrindo a capacidade de manutenção das aplicações que utilizassem o framework.

Para solucionar este problema, buscamos inspiração nas linguagens orientadas a objeto $(\mathrm{OO})$ que possuem como um dos principais objetivos facilitar o reaproveitamento de código e de componentes de software (Larman04). Projetamos o KnowledgeFlow tomando emprestado do universo OO os conceitos de herança e polimorfismo. Através da herança é possível criarmos estruturas de configuração com hierarquias complexas e, ainda assim, manter cada XML de configuração inteligível. Com o uso do polimorfismo, podemos redefinir comportamentos determinados no XML raiz. Esta combinação de conceitos se mostrou muito robusta para a resolução de problemas complexos, e nos possibilitou atingir os requisitos de simplicidade e flexibilidade da solução. 


\section{5}

\section{Diagrama XSD}

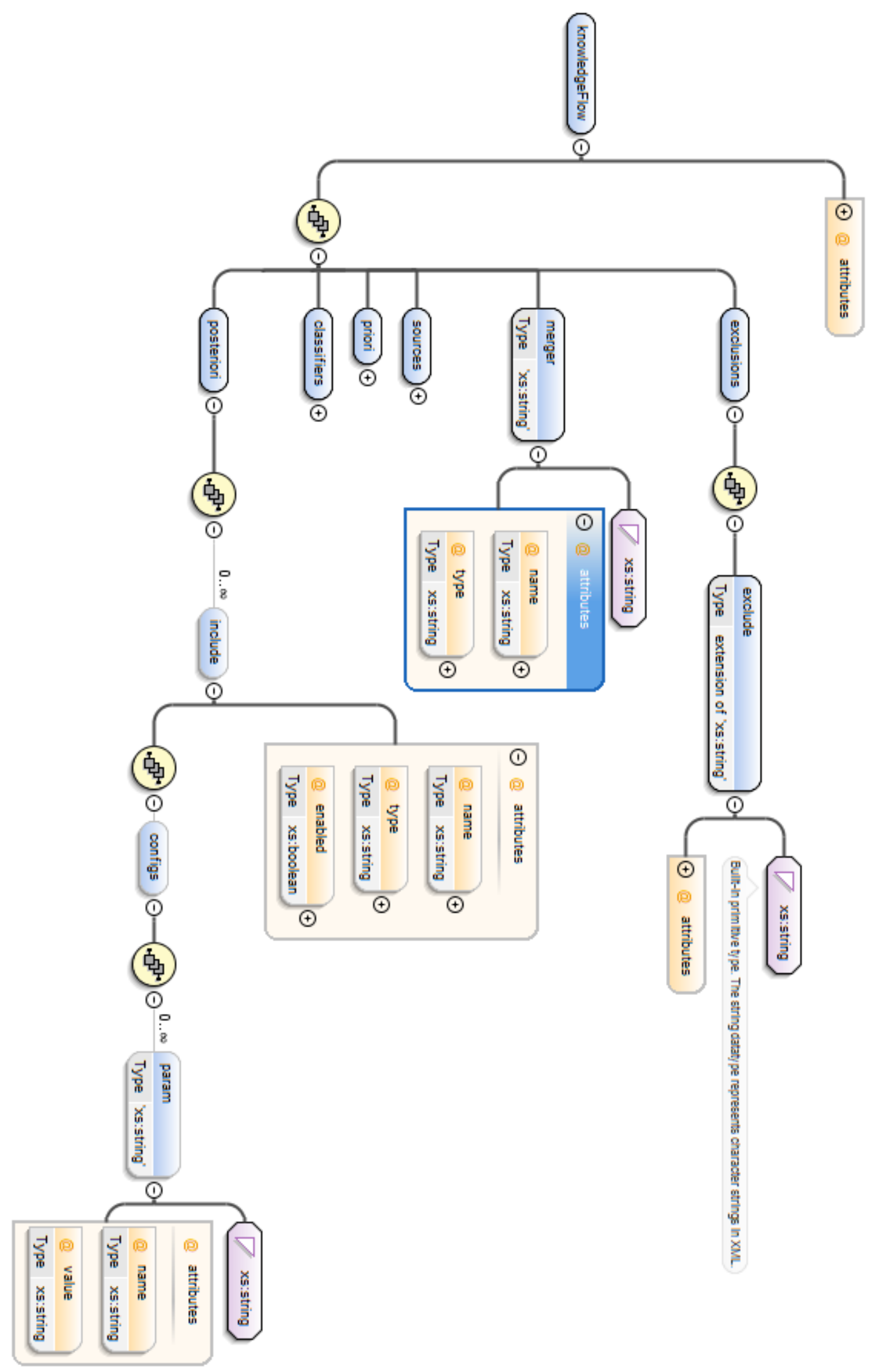

Figura 4.2: XSD - KnowledgeFlow 


\section{6}

\section{Elementos do XML de configuração}

Abaixo dissecamos cada elemento do XSD (figura4.2):

O nó KnowledgeFlow representa todo o fluxo de execução, e possui os seguintes atributos:

name Nome do KnowledgeFlow a ser configurado.

extends Permite especificar o nome do XML raiz (implementação da herança).

flow Permite definir a classe que irá controlar o fluxo de execução, caso seja necessário um fluxo de execução alternativo (deve herdar da classe MatcherFlowController).

O nó KnowledgeFlow possui sete blocos internos:

configs Permite passar parâmetros do tipo <param> para o FlowController.

sources Define o conjunto de DataSources que será utilizado ao longo da execução do fluxo, cada DataSource é adicionado pelo comando <include> (pacote Matcher.KFlow. Source, seção A.4).

priori Define os pré-processadores que serão utilizados para filtrar os $D a$ taSources, cada pré-processador é adicionado pelo comando <include> (pacote Matcher.KFlow.Priori, seção A.5).

merger Permite definir o InstanceMerger através do atributo type que deverá apontar para a classe a ser utilizada para a manipulação do ClassificationContext (pacote Matcher.KFlow.Merger, seção A.7).

classifier Especifica os componentes que serão utilizados para classificar as instâncias. Cada classificador é adicionado pelo comando <include> (pacote Matcher.KFlow.Classifier, seção A.6).

posteriori Define os elementos que serão utilizados para processar a saída do framework. Cada pós-processador é adicionado pelo comando <include> (pacote Matcher.KFlow.Posteriori, seção A.8).

exclusions Permite suprimir comportamentos de elementos definidos em níveis mais elevados na hierarquia dos arquivos de configuração. Cada exclusão pode ser definida pelo comando exclude. 
Os blocos de configuração <sources>, <priori>, <classifier> e $<$ posteriori>, utilizam-se do comando <include> para adicionarem seus elementos. Relacionamos abaixo os atributos da tag <include>:

name Nome do elemento a ser incluído.

type Classe a ser instanciada para o elemento incluído (deve herdar de MatcherPart)

enabled Permite habilitar ou desabilitar o elemento a ser incluído, facilitando os testes.

before Permite inserir o elemento corrente antes do elemento especificado por este atributo. Este atributo e utilizado para definir ou modificar a ordem de execução de cada elemento, em relação à toda a hierarquia de configuração).

configs:param Lista de parâmetros de configuração do tipo <param>.

\section{7 \\ Exemplos de configurações}

Para exemplificar o uso do XML de configuração do EasyLearn, elencamos o problema de classificação de e-mails em SPAM e NÃO SPAM pela sua simplicidade. Cada solução de Classificação precisa implementar os três processos mencionados no capítulo 3.

Para o exemplo abordado, o DataSource de entrada (RawSource) será um arquivo ARFF (Weka08) contendo duas colunas:

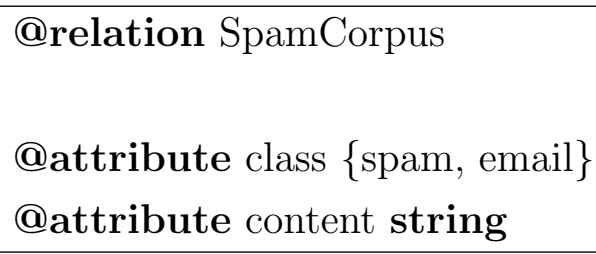

Figura 4.3: Estrutura do arquivo de entrada ARFF. 


\subsection{1}

\section{SpamParent}

Como alguns processos possuem interseções em relação às suas operações, recomendamos criar um arquivo de configuração raíz contendo as partes comuns aos processos, com este propósito criamos o arquivo SpamParent (listagem 1). Este arquivo contém a lista de pre-processadores (<priori >) que serão utilizados por todos os arquivos XML que herdam de SpamParent, além dos classificadores (<classifiers $\rangle$ ) e dos elementos de pós-processamento $(<$ posteriori $>$ ).

Elementos do XML raíz:

- priori

1. StringNormalizer: padronização da entrada.

2. ExtractorPlaceHolder: facilita a inclusão de novas partes pelos XML filhos. Facilitando a extração de atributos, por exemplo, antes do processo de tokenização.

3. StringTokenizer: Cria a matriz de atributos (bag of words) para o campo content do DataSource.

4. DatasetSplitter: Separa o DataSource em dois.

- classifiers

1. J48: algoritmo de classificação utilizando árvore de decisão.

2. SMO: algoritmo de classificação utilizando SVM.

- posteriori

1. CrossValidateEvaluateClassifier: executa a validação cruzada 2folds sobre o DataSource completo.

2. EvaluateClassifier: realiza outra medida de avaliação de precisão com o DataSource EvalSource. 


\subsection{2}

\section{SpamEval}

O arquivo SpamEval (listagem 2) é responsável por implementar o processo de avaliação descrito na seção 3.2 e herda do arquivo SpamParent.

Elementos do XML SpamEval:

- source

1. RawSource: arquivo de entrada ARFF definido na listagem 4.7.

- priori

1. Synonym: substitui os sinônimos do corpo do email (content) por palavras com o mesmo significado. Incluído antes do ExtractorsPlaceHolder definido no arquivo SpamParent.

2. MixedWordModel: substitui palavras misturadas com números por suas correspondentes, contendo apenas letras (ex: V1AGRA $\rightarrow$ VIAGRA).

\subsection{3}

\section{SpamLearn}

O arquivo SpamLearn (listagem 3) é responsável por implementar o processo de aprendizado descrito na seção 3.3 e herda do arquivo SpamEval, omitindo alguns comportamentos (<exclusions>).

Elementos do XML SpamLearn:

- exclusions Todos os elementos relativos ao processo de avaliação são excluído do processo de aprendizado.

- posteriori

1. RenameSource: renomeia o DataSource completo (RawSource) para LearnSource, de modo a poder ser utilizado pelos classificadores declarados no arquivo SpamParent.

2. SerializeClassifier: persiste os classificadores na base de conhecimento (KnowledgeBase), com o nome de SpamModel.<nome do classificador> (o nome do classificador é utilizado como extensão do arquivo). 


\subsection{4}

\section{SpamClassify}

O arquivo SpamClassify (listagem 4) é responsável por implementar o processo de classificação descrito na seção 3.4.

Elementos do XML SpamClassify:

- merger FilterMerger padrão, utilizado para recuperar o MultiFilter persistido na KnowledgeBase.

\section{- sources}

1. RawSource: carrega o conjunto de emails reais para serem classificados.

1. SMO: utiliza o SMO já treinado para classificar os dados do RawSource. 


\section{5 \\ Estudo de Caso: Classificação Ofertas de Produtos}

\section{1}

\section{Requisitos}

Para cumprir com sucesso o caso de classificação de produtos, o framework desenvolvido deve ser capaz de endereçar as seguintes questões relativas ao domínio do problema escolhido:

- Aprender a classificar produtos do ecommerce através de descrições de ofertas.

- Manter um modelo de atributos por categoria.

- Permitir que o modelo aprendido seja atualizado periodicamente, possibilitando correções e inserções de novas classes.

- Selecionar os atributos mais relevantes para cada categoria.

- Facilitar a escolha dos melhores classificadores para cada ocasião.

- Prover ferramental para corrigir o texto das descrições, caso haja algum erro de digitação.

- Acompanhar e guardar os resultados das medições de forma organizada, por categoria.

- Permitir gerar e gerenciar novas configurações para os datasets de treinamento e avaliação. Desta forma, poderíamos ter $\mathbf{N}$ datasets por categoria, melhorando a precisão das medições.

\section{2}

\section{Corpus}

Como visto em (Kotsiantis07), o primeiro passo para resolver qualquer problema de Aprendizado Supervisionado é a obtenção do Corpus. Isto é, a coleta das informações disponíveis acerca do problema a ser tratado. Além disto, a acurácia da solução gerada está fortemente ligada à qualidade do conjunto de dados. Neste capítulo discutimos os procedimentos e cuidados empregados na construção do corpus que foi utilizado ao longo dos experimentos apresentados nos capítulos seguintes. 


\subsection{1}

\section{Construção}

Criação da base de dados para aprendizado de máquina é geralmente uma tarefa árdua e demorada, pois, quase sempre, é necessária intervenção manual para a construção dos gabaritos.

Contudo, neste caso, alguns comparadores de preço resolvem bem este problema para fins comerciais (não sabemos se eles resolvem de forma automática). Para automatizar o processo de construção do Corpus, criamos um web scraper, isto é, um robô para percorrer algumas páginas da internet em busca de informações para compor o dataset. Apesar de simplificar o processo, nos deparamos com alguns desafios durante a execução do scraper, já que a maioria dos web sites fornecem muitos entraves e barreiras, tornando este processo demorado. Relacionamos abaixo alguns dos problemas enfrentados:

- Grande demanda de banda, memória e CPU

- Bloqueio de IP no servidor alvo pela alta quantidade de requisições

- CAPTCHA anti-robôs

- Ausência de padrões no HTML entre as categorias

- Hierarquia complexa, com categorias, produtos e ofertas separadas por páginas.

- Javascript e AJAX que dificultam o processamento do HTML

- Inconsistências nos dados, como categorias duplicadas e produtos mal classificados.

Desta forma, nosso corpus foi construído em cima das listas de ofertas presentes em alguns web sites brasileiros de comparação de preço. Estas listas são divididas por categorias de produtos, como apresentado na figura 5.1.

Para cada categoria existe uma lista de produtos associados (SKU). Esta lista de produtos é uma camada abstrata, criada pelos sites de comparação de preço para agregar ofertas de um mesmo produto. Na figura 5.2, mostramos um produto da categoria Televisão. A descrição

"Sony Bravia KDL-40BX425 LCD Plana 40 Polegadas"é como o site de comparação de preços apresenta tal produto. Note que esta descrição diz respeito a uma classe de produto que pode ter descrições diferentes nos sites das lojas virtuais.

Chamaremos o produto da camada de SKU, dos sites de comparação de preços, de "classe de produto", e sua descrição de "descrição da classe". Para cada classe de produto existe uma lista de ofertas referentes a este produto nas lojas virtuais, como na figura 5.3. Cada produto comercializado por uma loja 


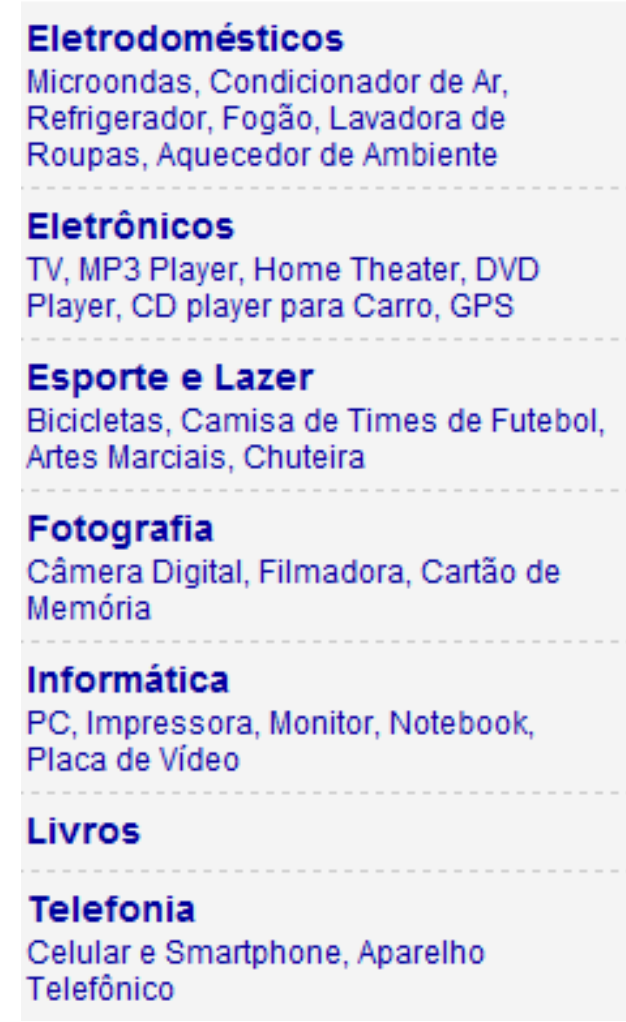

Figura 5.1: Categorias dos Produtos

virtual será chamado de oferta, e irá corresponder à uma instância da classe do produto.

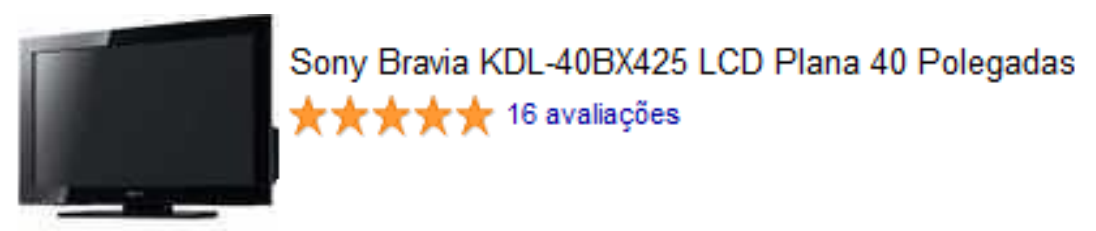

30 Ofertas

Figura 5.2: Classe de produto Sony Bravia KDL-40BX425

Desta forma, as instâncias (ofertas) são as descrições dos produtos nas lojas virtuais e sabemos que descrições são relativas ao mesmo produto se elas correspondem à mesma classe do produto abstrato no site de comparação de preços.

\section{2 .2}

\section{Domínio Analisado}

Nós fizemos scraping de todas as categorias disponíveis no web site de comparação de preço, o que inclui diversos tipos de produtos como televisores, monitores, CDs, livros, etc. Pelo domínio extenso que estamos lidando, o 

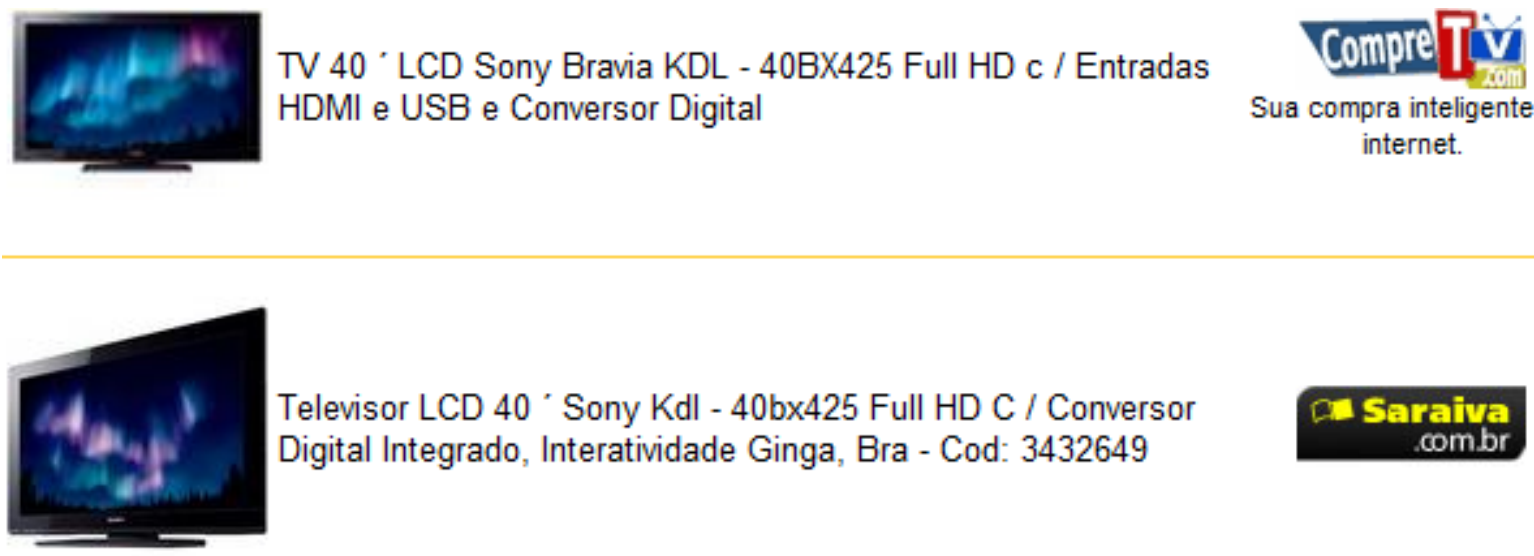

Televisor LCD 40 ' Sony Kdl - 40bx425 Full HD C / Conversor Digital Integrado, Interatividade Ginga, Bra - Cod: 3432649

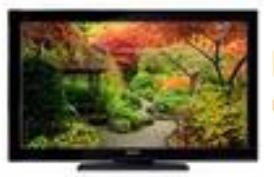

Linha 2011: TV LCD Sony Bravia BX425 com 40 'Full HD com

Conversor Digital Integrado, Sensor de Lumi - cod. 10328

SONY

Figura 5.3: Instâncias do produto Sony Bravia KDL-40BX425 em diversas lojas

grau de dificuldade da classificação pode variar muito entre as categorias. Para o estudo de caso, selecionamos duas categorias: Televisão e Monitor. Apesar de aparentarem exigir o mesmo esforço de modelagem, são categorias bem distintas quando olhamos mais de perto para as características de suas instâncias.

A categoria de televisores, possui instâncias com descrições desordenadas e com um padrão não muito óbvio, enquanto a categoria de monitor contém instâncias com descrições bem mais regulares e previsíveis.

Com isso iremos necessitar de dois DataSources, um para Televisores e outra para Monitores. O DataSource de Televisores contém 2037 ofertas com 287 produtos, já o de Monitores contém 1592 ofertas com 145 produtos.

O banco de dados gerado contém, para cada classe de produto, uma série de ofertas reais correspondentes a esse produto (instâncias). Refletindo o fato de só ser necessário descobrir a classe de produto de cada oferta. Assim, nosso problema agora é: Dada uma oferta de loja virtual (de TV ou Monitor), qual é a classe de produto relacionado à ela?

\section{2 .3}

\section{Validação Cruzada}

Verificar manualmente a acurácia de cada teste inviabilizaria qualquer experimento. Evidentemente, este não foi o procedimento empregado para 
realizar nossas medições, ao invés disto, utilizamos um artifício chamado de Validação Cruzada, já mencionado na seção 3.2. Para acompanhar nossos progressos ao longo da fase de Engenharia de Atributos, dividimos, para cada categoria, nossos DataSources originais em dois DataSources menores:

1. Conjunto de Treino (TV e Monitor)

2. Conjunto de Validação (TV e Monitor)

É através do conjunto de treino que os classificadores irão aprender as associações entre as classes e as instâncias. Já na fase de validação, para cada instância do conjunto de validação, verificamos qual é o palpite da classe, sugerido pelo classificador, e comparamos com a classe correta que está cadastrada no dataset. Desta forma, conseguimos medir a acurácia do nosso modelo.

\subsection{4}

\section{Divisão do DataSource}

Decidimos que aproximadamente $75 \%$ das ofertas seriam utilizadas para treino e o restante para a avaliação da qualidade das estratégias. Sendo assim, obtivemos os seguintes números:

\begin{tabular}{|c|c|c|}
\hline Dataset & Treino & Validação \\
\hline Monitores & 1278 & 315 \\
\hline Televisores & 1575 & 460 \\
\hline
\end{tabular}

\section{2 .5}

\section{Características Gerais}

O dataset completo contém 185 categorias, totalizando 194499 classes e 1991849 instâncias - uma média de 10,2 instâncias por classe. Não estamos considerando nesses números classes com apenas uma instância. Abaixo listamos as maiores categorias: 


\section{3}

\section{Resultados}

Aqui apresentamos os resultados obtidos pelos algoritmos NaiveBayes, VFI, NNge e J48 com diferentes modelagens.

\subsection{1}

Monitor

Modelo Inicial

\begin{tabular}{|c|c|c|c|}
\hline Classifier & Acertos & Tempo de aprendizado(ms) & Tempo de avaliação(ms) \\
\hline NaiveBayes & $22.5397 \%$ & 296 & 3829 \\
\hline VFI & $93.0159 \%$ & 344 & 4921 \\
\hline NNge & $77.7778 \%$ & 45703 & 8094 \\
\hline J48 & $90.1587 \%$ & 6766 & 141 \\
\hline
\end{tabular}

\begin{tabular}{llll} 
Categoria & Classes & Instancias & Média \\
\hline Livros & 163118 & 1807784 & 11,1 \\
Jogos & 2906 & 18160 & 6,2 \\
Perfume & 2488 & 16333 & 6,6 \\
Relógio de Pulso & 2845 & 10835 & 3,8 \\
Tênis & 1069 & 10310 & 9,6 \\
Cartucho para Impressora & 406 & 4174 & 10,3 \\
Bonecos e Personagens & 948 & 3736 & 3,9 \\
Câmera Digital & 220 & 3672 & 16,7 \\
Circulador / Ventilador & 332 & 3118 & 9,4 \\
Kit de Som / Alto-Falante para Automóveis & 652 & 3015 & 4,6 \\
Fone de Ouvido / Headset & 503 & 2875 & 5,7 \\
Óculos de Sol & 733 & 2841 & 3,9 \\
Mouse & 564 & 2784 & 4,9 \\
Cadeira para Auto & 247 & 2698 & 10,9 \\
Jogos Diversos & 579 & 2664 & 4,6 \\
Bonecas & 591 & 2525 & 4,3 \\
Notebook & 481 & 2399 & 5 \\
Fogão & 425 & 2339 & 5,5 \\
PC & 349 & 2297 & 6,6 \\
Bicicleta & 310 & 2290 & 7,4 \\
Chuteira & 283 & 2200 & 7,8 \\
HD & 349 & 2158 & 6,2 \\
Impressora & 190 & 2154 & 11,3 \\
TV Aparelho Telefônico & 287 & 2037 & 7,1 \\
Monitor & 161 & 1633 & 10,1 \\
Camisa de Times de Futebol & 145 & 1592 & 11 \\
Refrigerador & 303 & 1585 & 5,2 \\
& 201 & 1585 & 7,9 \\
Mon & &
\end{tabular}

Tabela 5.1: Maiores categorias 
Modelo inicial com stopwords

\begin{tabular}{|c|c|c|c|}
\hline Classifier & Acertos & Tempo de aprendizado(ms) & Tempo de avaliação(ms) \\
\hline NaiveBayes & $23.1746 \%$ & 187 & 3703 \\
\hline VFI & $92.6984 \%$ & 187 & 4735 \\
\hline NNge & $78.7302 \%$ & 42984 & 7407 \\
\hline J48 & $90.1587 \%$ & 6219 & 94 \\
\hline
\end{tabular}

Modelo inicial com novo atributo marca

\begin{tabular}{|c|c|c|c|}
\hline Classifier & Acertos & Tempo de Aprendizado(ms) & Tempo de avaliação (ms) \\
\hline NaiveBayes & $25.0794 \%$ & 188 & 3766 \\
\hline VFI & $93.0159 \%$ & 156 & 4797 \\
\hline NNge & $79.3651 \%$ & 44860 & 7937 \\
\hline J48 & $89.2063 \%$ & 6312 & 94 \\
\hline
\end{tabular}

Modelo inicial mais atributo modelo

\begin{tabular}{|c|c|c|c|}
\hline Classifier & Acertos & Tempo de aprendizado(ms) & Tempo de avaliação(ms) \\
\hline NaiveBayes & $25.0794 \%$ & 187 & 3813 \\
\hline VFI & $94.9206 \%$ & 156 & 4797 \\
\hline NNge & $95.2381 \%$ & 42203 & 6703 \\
\hline J48 & $89.8413 \%$ & 5891 & 78 \\
\hline
\end{tabular}

Modelo inicial mais atributo tamanho

\begin{tabular}{|c|c|c|c|}
\hline Classifier & Acertos & Tempo de aprendizado(ms) & Tempo de avaliação (ms) \\
\hline NaiveBayes & $23.8095 \%$ & 297 & 3844 \\
\hline VFI & $93.6508 \%$ & 360 & 4953 \\
\hline NNge & $79.3651 \%$ & 45422 & 7968 \\
\hline J48 & $88.8889 \%$ & 7156 & 141 \\
\hline
\end{tabular}

Modelo inicial mais atributo tipo

\begin{tabular}{|c|c|c|c|}
\hline Classifier & Acertos & Tempo de aprendizado(ms) & Tempo de avaliação(ms) \\
\hline NaiveBayes & $23.8095 \%$ & 297 & 3875 \\
\hline VFI & $93.0159 \%$ & 344 & 4938 \\
\hline NNge & $78.7302 \%$ & 45375 & 8047 \\
\hline J48 & $89.8413 \%$ & 6578 & 141 \\
\hline
\end{tabular}


Modelo inicial mais replicação de instâncias

\begin{tabular}{|c|c|c|c|}
\hline Classifier & Acertos & Tempo de aprendizado(ms) & Tempo de avaliação(ms) \\
\hline NaiveBayes & $22.5397 \%$ & 204 & 4015 \\
\hline VFI & $93.0159 \%$ & 250 & 4781 \\
\hline NNge & $77.7778 \%$ & 45406 & 8063 \\
\hline J48 & $90.1587 \%$ & 6453 & 110 \\
\hline
\end{tabular}

Modelo inicial, mais todos os atributos, mais replicação das instâncias, mais stopwords.

\begin{tabular}{|c|c|c|c|}
\hline Classifier & Acertos & Tempo de aprendizado(ms) & Tempo de avaliação(ms) \\
\hline NaiveBayes & $27.3016 \%$ & 203 & 4047 \\
\hline VFI & $95.5556 \%$ & 343 & 4907 \\
\hline NNge & $96.8254 \%$ & 41937 & 6438 \\
\hline J48 & $89.8413 \%$ & 5469 & 93 \\
\hline
\end{tabular}

\subsection{2}

TV

Modelo inicial

\begin{tabular}{|c|c|c|c|}
\hline Classifier & Acertos & Tempo de aprendizado(ms) & Tempo de avaliação(ms) \\
\hline NaiveBayes & $5 \%$ & 390 & 11938 \\
\hline VFI & $87.3913 \%$ & 375 & 13546 \\
\hline NNge & $65.4348 \%$ & 99985 & 22031 \\
\hline J48 & $74.5652 \%$ & 16735 & 515 \\
\hline
\end{tabular}

Modelo inicial mais stopwords

\begin{tabular}{|c|c|c|c|}
\hline Classifier & Acertos & Tempo de aprendizado(ms) & Tempo de avaliação(ms) \\
\hline NaiveBayes & $5.2174 \%$ & 235 & 11312 \\
\hline VFI & $87.1739 \%$ & 265 & 13219 \\
\hline NNge & $67.1739 \%$ & 98266 & 21781 \\
\hline J48 & $74.3478 \%$ & 16313 & 469 \\
\hline
\end{tabular}

Modelo inicial mais atributo marca

\begin{tabular}{|c|c|c|c|}
\hline Classifier & Acertos & Tempo de aprendizado(ms) & Tempo de avalição(ms) \\
\hline NaiveBayes & $5.8696 \%$ & 313 & 11531 \\
\hline VFI & $88.6957 \%$ & 313 & 13562 \\
\hline NNge & $72.1739 \%$ & 126625 & 24562 \\
\hline J48 & $85.2174 \%$ & 20422 & 500 \\
\hline
\end{tabular}


Modelo inicial mais atributo modelo

\begin{tabular}{|c|c|c|c|}
\hline Classifier & Acertos & Tempo de aprendizado(ms) & Tempo de avaliação(ms) \\
\hline NaiveBayes & $6.087 \%$ & 297 & 11469 \\
\hline VFI & $90.2174 \%$ & 312 & 13579 \\
\hline NNge & $90 \%$ & 123218 & 21157 \\
\hline J48 & $84.7826 \%$ & 20937 & 484 \\
\hline
\end{tabular}

Modelo inicial mais atributo tamanho

\begin{tabular}{|c|c|c|c|}
\hline Classifier & Acertos & Tempo de aprendizado(ms) & Tempo de avaliação(ms) \\
\hline NaiveBayes & $6.087 \%$ & 296 & 11454 \\
\hline VFI & $89.3478 \%$ & 297 & 13609 \\
\hline NNge & $73.0435 \%$ & 125141 & 24406 \\
\hline J48 & $85.2174 \%$ & 19891 & 484 \\
\hline
\end{tabular}

Modelo inicial mais atributo tipo

\begin{tabular}{|c|c|c|c|}
\hline Classifier & Acertos & Tempo de aprendizado(ms) & Tempo de avaliação(ms) \\
\hline NaiveBayes & $5.4348 \%$ & 297 & 11484 \\
\hline VFI & $88.6957 \%$ & 312 & 13594 \\
\hline NNge & $71.087 \%$ & 125860 & 24828 \\
\hline J48 & $85.4348 \%$ & 20016 & 500 \\
\hline
\end{tabular}

Modelo inicial mais replicação de instâncias

\begin{tabular}{|c|c|c|c|}
\hline Classifier & Acertos & Tempo de aprendizado(ms) & Tempo de avaliação(ms) \\
\hline NaiveBayes & $5.4348 \%$ & 297 & 11484 \\
\hline VFI & $88.6957 \%$ & 313 & 13562 \\
\hline NNge & $70.2174 \%$ & 126625 & 25047 \\
\hline J48 & $85.4348 \%$ & 20219 & 515 \\
\hline
\end{tabular}

Modelo inicial, mais todos os atributos, mais stopwords, mais replicação

\begin{tabular}{|c|c|c|c|}
\hline Classifier & Acertos & Tempo de aprendizado(ms) & Tempo de avaliação(ms) \\
\hline NaiveBayes & $7.3913 \%$ & 296 & 11485 \\
\hline VFI & $91.5217 \%$ & 312 & 13469 \\
\hline NNge & $91.087 \%$ & 123390 & 21344 \\
\hline J48 & $84.7826 \%$ & 18391 & 438 \\
\hline
\end{tabular}




\subsection{3}

\section{Exemplos de Resultados da Classificação de TV}

A seguir forma relacionados alguns exemplos de televisores (seção 5.3.3) processados por um dos classificadores do EasyLearn. A primeira coluna contém as descrições das ofertas nas lojas virtuais e a segunda coluna indica a classe encontrada pelo classificador.

\begin{tabular}{|c|c|}
\hline Instância & Classe \\
\hline $\begin{array}{l}\text { TV 26" LCD AOC D26W931 c/ En- } \\
\text { tradas HDMI e USB e Conversor Di- } \\
\text { gital + Antena Interna Sagna Baby } \\
\text { Amplificada UHF, VHF e Digital }\end{array}$ & aoc d26w931 led plana 26 polegadas \\
\hline $\begin{array}{l}\text { TV 26" LCD AOC D26W931 c/ En- } \\
\text { tradas HDMI e USB e Conversor Di- } \\
\text { gital + Limpador de Tela Diamond } \\
\text { + Cabo HDMI Diamond Cable } 1,5 \mathrm{~m}\end{array}$ & aoc d26w931 lcd plana 26 polegadas \\
\hline $\begin{array}{l}\text { TV 32"LCD - D32W931 - (1366 } \\
\text { x 768) com Conversor Digital Inte- } \\
\text { grado, } 3 \text { Entradas HDMI Entrada } \\
\text { USB - AOC }\end{array}$ & aoc d32w931 lcd plana 32 polegadas \\
\hline $\begin{array}{l}\text { Televisor LCD 32" CCE Stile D3201 } \\
\text { HDTV C/ Conversor Digital Inte- } \\
\text { grado, Anti-reflexo, } 2 \text { Hdm... cce d } 32 \\
\text { lcd plana } 32 \text { polegadas }\end{array}$ & cce d32 lcd plana 32 polegadas \\
\hline TV 14"CCE Cars HDC-142 & $\begin{array}{l}\text { cce disney hdw } 143 \text { crt convencional } \\
14 \text { polegadas }\end{array}$ \\
\hline TV 14" CCE Princess HDP-141 & $\begin{array}{l}\text { cce disney hdw } 143 \text { crt convencional } \\
14 \text { polegadas }\end{array}$ \\
\hline $\begin{array}{l}\text { TV 32" LCD - } 3203 \text { HD - } 2 \text { Entradas } \\
\text { HDMI - H-Buster }\end{array}$ & $\begin{array}{l}\text { h buster hbtv } 3203 \text { lcd plana } 32 \text { po- } \\
\text { legadas }\end{array}$ \\
\hline $\begin{array}{l}\text { TV 21"Tela Plana - 21FJ6RB - c/ } \\
\text { Closed Caption - LG }\end{array}$ & lg flat $21 \mathrm{fj} 6 \mathrm{r}$ crt plana 21 polegadas \\
\hline $\begin{array}{l}\text { TV 26" LCD 26PFL3404 (1366 x } 768 \\
\text { pixels), } 2 \text { Entradas HDMI - Philips }\end{array}$ & $\begin{array}{l}\text { philips } 26 \text { pfl3404 lcd plana } 26 \text { pole- } \\
\text { gadas }\end{array}$ \\
\hline $\begin{array}{l}\text { Smart TV LED Samsung D5500 } \\
\text { com 40" Full HD, Clear Motion Rate } \\
\text { 120Hz, Smart Hub e Samsung Apps } \\
\text { - UN40D5500RGX }\end{array}$ & $\begin{array}{l}\text { samsung un40d5500 led plana } 40 \text { po- } \\
\text { legadas }\end{array}$ \\
\hline
\end{tabular}




\section{6 \\ Conclusão}

Neste trabalho utilizamos técnicas de aprendizado supervisionado para apresentar uma solução ao problema de classificação de ofertas de produtos do comércio eletrônico, cujo o objetivo é identificar se uma determinada oferta de um produto em uma loja virtual corresponde a um produto já catalogado previamente. Para cumprir o objetivo deste trabalho, construímos um corpus para apoiar as técnicas de aprendizado supervisionado, realizamos a engenharia de atributos para extrair atributos relevantes a partir da descrição da oferta - que é o único atributo disponível à priori, por fim, criamos o EasyLearn, um framework para apoiar o desenvolvimento de aplicações voltadas ao aprendizado supervisionado. Utilizamos o framework desenvolvido para resolver o problema supracitado de forma simples e elegante. Além disto, demonstramos o potencial da infra-estrutura criada demonstrando outras aplicações relacionadas ao aprendizado supervisionado.

Apresentamos o problema de classificação de ofertas de produtos como um estudo de caso do EasyLearn.

O EasyLearn recebe como entrada um conjunto de arquivos de configuração no formato XML contendo a definição do fluxo de processamento a ser executado, além do DataSource a ser processado - independente do formato. Sua saída é customizável, e pode ser configurada para produzir, por exemplo, relatórios de acurácia da classificação, o próprio DataSource classificado, ou o modelo de classificação já treinado.

A arquitetura do EasyLearn foi definida após a análise detalhada dos processos de Classificação, onde identificamos inúmeras atividades em comum entre os três processos estudados (aprendizado, avaliação e classificação). Através desta percepção e tomando as linguagens Orientadas à Objetos como inspiração, criamos um framework capaz de comportar os processos de classificação e suas possíveis variações, além de permitir o reaproveitamento das configurações, através da implementação de herança e polimorfismo para os seus arquivos de configuração.

Ilustramos o uso do framework criado através de um estudo de caso completo sobre classificação de produtos do comércio eletrônico - incluindo a 
criação do corpus, engenharia de atributos e análise dos resultados obtidos.

Para solucionar o problema de classificação de produtos, inicialmente, buscamos uma abordagem totalmente baseada no WEKA, sem a utilização do EasyLearn. Entretanto, em função da complexidade do problema a ser resolvido, esbarramos em inúmeros desafios ao utilizar a API do WEKA, entre eles:

- Complexidade da API.

- Necessidade de conhecimento apurado em desenvolvimento JAVA.

- Mensagens de erro pouco intuitivas que não apontavam devidamente para a causa do problema.

- Dificuldade para alterar o fluxo de execução definido inicialmente.

Para lidar com os desafios elencados, o EasyLearn se mostrou eficaz, tornando a solução elaborada simples, modular e escalável para as inúmeras categorias do estudo de caso proposto.

Por fim, como trabalhos futuros, sugerimos:

Novas operações de Aprendizado de Máquina O Weka apoia o desenvolvimento de aplicações para aprendizado supervisionado e nãosupervisionado, entretanto o EasyLearn suporta apenas os classificadores do Weka, isto é, apenas as classes de aprendizado supervisionado. O próximo passo a ser dado é suportar um fluxo de execução para englobar operações de agregação, regressão, associação e outros procedimentos suportados pelo Weka.

Classificação em tempo real Alguns classificadores podem ser atualizados progressivamente, isto é, sem a necessidade de refazer todo o modelo a cada nova atualização do corpus, estes classificadores no Weka herdam da classe UpdatableClassifier. A princípio, o EasyLearn suportaria um fluxo de conhecimento que utilize classificadores atualizáveis sem a necessidade de modificações na API. No entanto, para termos esta garantia será necessário um estudo adicional nesta direção.

Interface Gráfica Outro caminho a ser trilhado é a criação de uma interface gráfica para facilitar a construção dos $X M L$ de configuração. O Weka já possui uma interface que permite desenhar um fluxo de execução, no entanto, ao salvar o trabalho feito nesta interface, é gerado um arquivo binário em um formato do Weka. Além disto, através desta interface, não é possível reaproveitar partes de fluxos de execução definidos em outros momentos do desenvolvimento da solução, o que nos obriga a construir todo o fluxo do início. 
Criação de camada de abstração Nesta versão do EasyLearn, toda a infra-estrutura criada é apoiada sobre o framework Weka, o ideal é que o EasyLearn possua as suas próprias abstrações e conceitos e utilize o Weka como um dos várias frameworks de Aprendizado de Máquina. Desta forma, novos frameworks poderiam ser integrados ao EasyLearn, nos abrindo um leque de possibilidades. 


\section{Referências Bibliográficas}

Alpaydin04. ALPAYDIN, E.. Introduction to machine learning. Adaptive computation and machine learning. MIT Press, 2004.

Barnett94. BARNETT, V.; LEWIS, T.. Outliers in Statistical Data. Wiley Series in Probability \& Statistics. Wiley, Apr. 1994.

Batista03. BATISTA, G. E. A. P. A.; MONARD, M. C.. An Analysis of Four Missing Data Treatment Methods for Supervised Learning. Applied Artificial Intelligence, 17:519-533, 2003.

Fellbaum98. FELLBAUM, C.. WordNet: An Electronic Lexical Database. Bradford Books, 1998.

Fowler02. FOWLER, M.. Patterns of Enterprise Application Architecture. Addison-Wesley Longman Publishing Co., Inc., Boston, MA, USA, 2002.

Gamma95. GAMMA, E.; HELM, R.; JOHNSON, R. ; VLISSIDES, J.. Design patterns: elements of reusable object-oriented software. AddisonWesley Longman Publishing Co., Inc., Boston, MA, USA, 1995.

Hand98. HAND, D.; S.D.JACKA. Consumer credit and statistics. in statistics in finance. p. 69-81, 1998. London.

Hastie08. HASTIE, T.; TIBSHIRANI, R. ; FRIEDMAN, J.. The elements of statistical learning: data mining, inference, and prediction. Springer series in statistics. Springer, 2008.

Hodge04. HODGE, V.; AUSTIN, J.. A survey of outlier detection methodologies. Artif. Intell. Rev., 22(2):85-126, Oct. 2004.

Indurkhya10. INDURKHYA, N.; DAMERAU, F. J.. Handbook of Natural Language Processing. Chapman \& Hall/CRC, 2nd edition, 2010.

Jaakkola98. JAAKKOLA, T.; HAUSSLER, D.. Exploiting generative models in discriminative classifiers. In: IN ADVANCES IN NEURAL INFORMATION PROCESSING SYSTEMS 11, p. 487-493. MIT Press, 1998. 
Kegelmeyer02. CHAWLA, N. V.; BOWYER, K. W.; HALL, L. O. ; KEGELMEYER, W. P.. Smote: Synthetic minority over-sampling technique. Journal of Artificial Intelligence Research, 16:321-357, 2002.

Kotsiantis07. KOTSIANTIS, S. B.. Supervised machine learning: A review of classification techniques. informatica 31:249?268, 2007.

Kukich92. KUKICH, K.. Techniques for automatically correcting words in text. ACM Comput. Surv., 24(4):377-439, Dec. 1992.

Larman04. LARMAN, C.. Applying UML and Patterns: An Introduction to Object-Oriented Analysis and Design and Iterative Development (3rd Edition). Prentice Hall PTR, Upper Saddle River, NJ, USA, 2004.

Lewis98. LEWIS, D. D.. Naive (bayes) at forty: The independence assumption in information retrieval. In: ?, p. 4-15. Springer Verlag, 1998.

Manning99. MANNING, C. D.; SCHÜTZE, H.. Foundations of statistical natural language processing. MIT Press, Cambridge, MA, USA, 1999.

Maron61. MARON, M. E.. Automatic indexing: An experimental inquiry. J. ACM, 8:404-417, July 1961.

Markovitch02. MARKOVITCH, S.; ROSENSTEIN, D.. Feature generation using general constructor functions. Machine Learning, 49:59-98, 2002. $10.1023 / A: 1014046307775$.

Michie94. MICHIE, D.; SPIEGELHALTER, D. ; TAYLOR, C.. Machine learning, neural and statistical classification. Artificial intelligence. Ellis Horwood, 1994.

Mitchell97. MITCHELL, T.. Machine Learning. McGraw-Hill series in computer science. McGraw-Hill, 1997.

Motoda01. LIU, H.; MOTODA, H.. Instance Selection and Construction for Data Mining. Kluwer Academic Publishers, Norwell, MA, USA, 2001.

Quinlan93. QUINLAN, J.. C4.5: programs for machine learning. Morgan Kaufmann series in machine learning. Morgan Kaufmann Publishers, 1993.

Simeon08. SIMEON, M.; HILDERMAN, R.. Categorical proportional difference: A feature selection method for text categorization. In: 
Roddick, J. F.; Li, J.; Christen, P. ; Kennedy, P. J., editors, SEVENTH AUSTRALASIAN DATA MINING CONFERENCE (AUSDM 2008), volumen 87 de CRPIT, p. 201-208, Glenelg, South Australia, 2008. ACS.

Smola08. SMOLA, A. J.; VISHWANATHAN, S.. Introduction to Machine Learning. Press Syndicate of the University of Cambridge, 2008.

Sproat01. SPROAT, R.; BLACK, A. W.; CHEN, S.; KUMAR, S.; OSTENDORF, M. ; RICHARDS, C.. Normalization of non-standard words. Computer Speech and Language, 15(3):1-40, 2001.

Teller00. Review of "speech and language processing: an introduction to natural language processing, computational linguistics, and speech recognition"by daniel jurafsky and james h. martin. prentice hall 2000. Comput. Linguist., 26(4):638-641, Dec. 2000. Reviewer-Teller, Virginia.

Thor. THOR, A.. Toward an adaptive string similarity measure for matching product offers.

Tompkins98. TOMPKINS, J.; SMITH, J.. Warehouse Management Handbook. Tompkins Press, 1998.

Unicode11. CONSORTIUM, T. U.. Unicode normalization forms. http://unicode.org/reports/tr15/, 08 2012. 31.

WebShoppers11. EBIT EMPRESA. Webshoppers - 24 ${ }^{\mathrm{a}}$ edição. http: //www.webshoppers.com.br/webshoppers/WebShoppers24.pdf, Agosto 2011.

Weka08. PROJECT, W. M. L.. Weka. http://www.cs.waikato.ac.nz/ ml/weka.

Woods93. WOODS, K. S.; DOSS, C. C.; BOWYER, K. W.; SOLKA, J. L.; PRIEBE, C. E. ; KEGELMEYER, W. P.. Comparative evaluation of pattern recognition techniques for detection of microcalcifications in mammography. International Journal of Pattern Recognition and Artificial Intelligence, 1993.

Yu2004. YU, L.; LIU, H.. Efficient feature selection via analysis of relevance and redundancy. J. Mach. Learn. Res., 5:1205-1224, Dec. 2004.

eSchool11. SCHOOL, E.. Informações do comércio eletrônico no brasil. http://www.camara-e.net/2011/09/01/comercio-eletronico-naoencontra-profissionais-qualificados/, 09 2011. 01. 


\section{A \\ Classes do EasyLearn}

A.1

Pacote Matcher

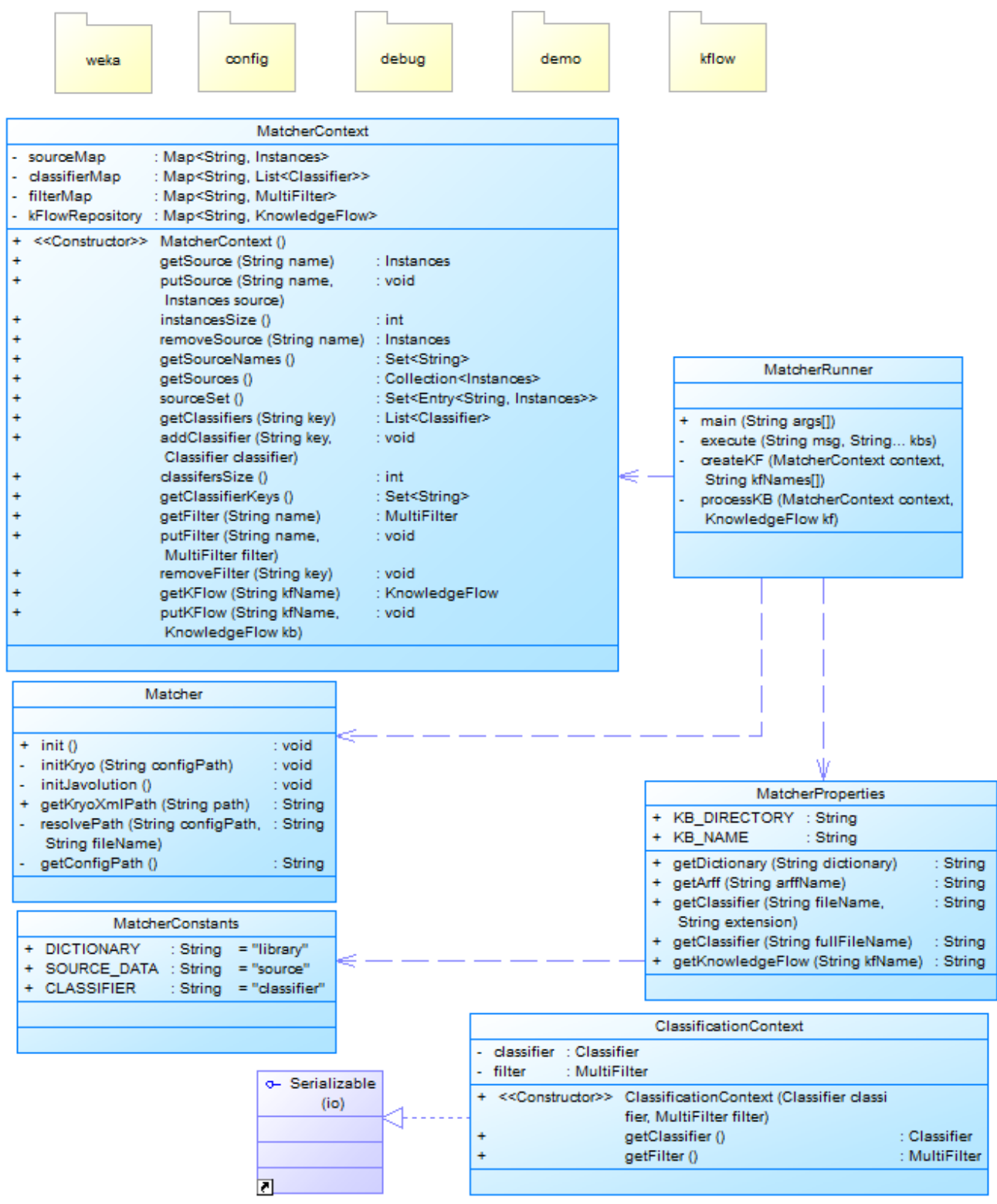

Figura A.1: Diagrama das classes do pacote Matcher 
MatcherRunner Este é o ponto de entrada da API. O MatcherRunner realiza a carga de todos os arquivos de configuração necessários, de forma ordenada, cria um MatcherContext e chama o MatcherFlowController (seção A.3) para iniciar fluxo escolhido (Avaliação, Aprendizado, Classificação, ou qualquer outro fluxo que siga os padrões definidos).

Matcher Ponto central de configuração da API, carregando todas as propriedades do framework, inicializando (Matcher. init()) serviços básicos de Serialização, Logging e qualquer outra biblioteca que necessite de configurações adicionais.

MatcherConstants Contém as constantes utilizadas no framework. Evita que as constantes de configuração fiquem espalhadas por todo o código-fonte.

MatcherContext Implementa o padrão de projeto Repository definido em (Fowler02). Conforme o MatcherFlowController executa cada uma de suas etapas, cada componente pode alterar o estado do MatcherContext, modificando o contexto corrente. O MatcherContext possui uma relação com todos os InstanceSource carregados pela execução do processo corrente, além de todos os classificadores utilizados. Através do MatcherContext é possível realizar qualquer operação sobre os conjuntos de dados abertos. Em suma, este objeto é responsável por guardar a saída da etapa anterior, que pode ser utilizada como entrada para a etapa seguinte.

MatcherProperties Provê e carrega todas as propriedades variáveis do framework, tais como configuração da API de logging, de serialização e de classificação. Além de manter as propriedades referentes ao diretório da KnowledgeBase a ser utilizada.

ClassificationContext Ao final do processo de aprendizado, é natural persistirmos o modelo gerado para ser utilizado futuramente, sobre um outro conjunto de dados. Para que o classificador seja útil ao ser carregado novamente (desserializado) precisamos realizar as mesmas operações (pré-processamento) que realizamos sobre o novo conjunto de dados, caso contrário, é possível que tenhamos um resultado inesperado, ou alguma incompatibilidade com os modelos gerados. Para solucionar este problema, temos que persistir não apenas o classificador, mas também, todo o seu contexto de classificação (ClassificationContext), isto é, os filtros aplicados sobre o conjunto de treino - já na ordem correta de execução. 


\section{A.2}

\section{Pacote Matcher.Config}

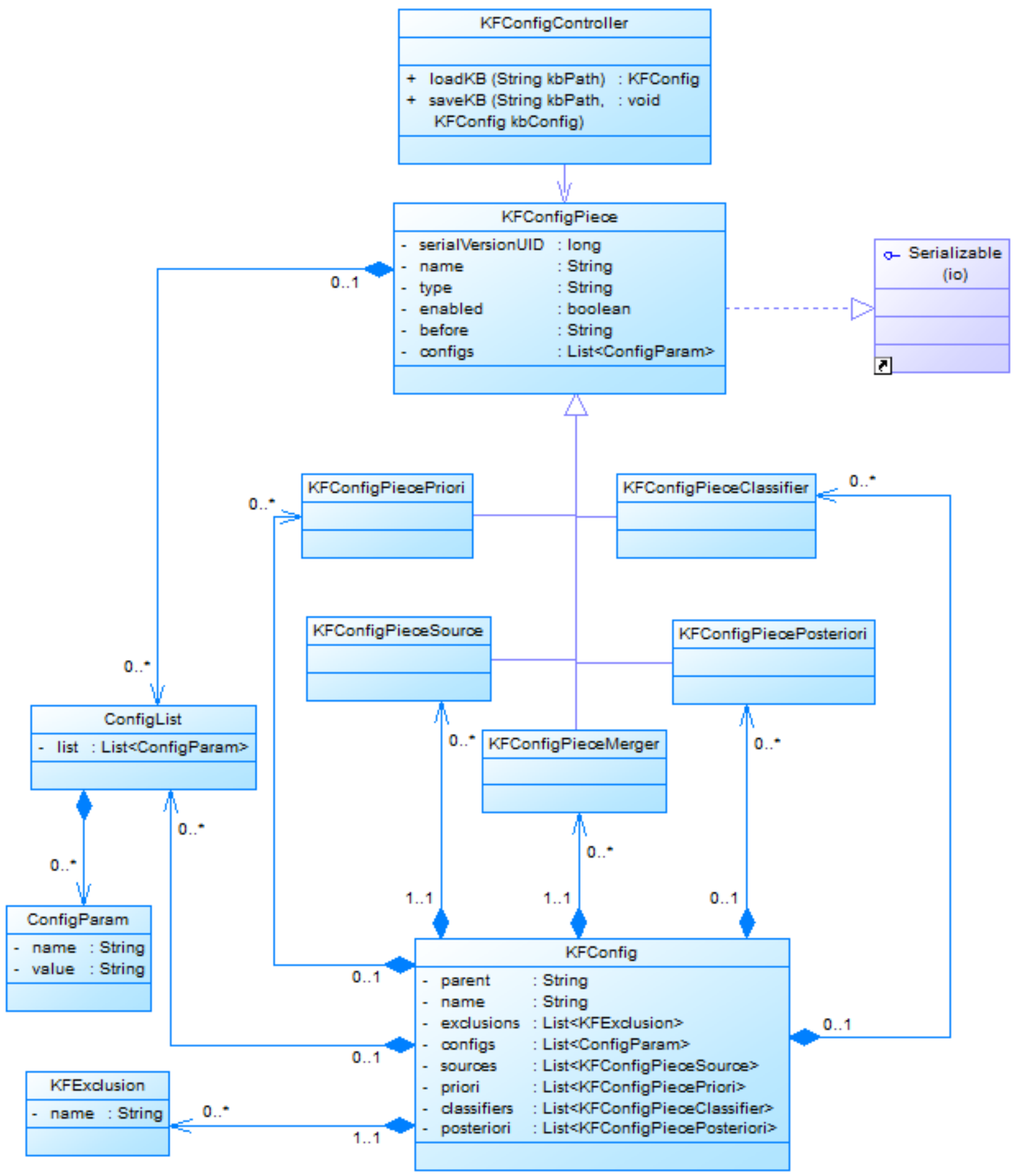

Figura A.2: Diagrama das classes do pacote Matcher.Config

KFConfigController Classe de entrada do módulo de configuração do EasyLearn, através do KFConfigController é possível, dado o caminho do arquivo de configuração do KnowledgeFlow, carregar o KFConfig correspondente. Para isto, o KFConfigController faz o parsing do arquivo de configuração 
informado como parâmetro do método loadKB. Esta classe também possibilita seguir pelo caminho inverso: dado um destino e um KFConfig, o KFConfigController persiste o conteúdo do KFConfig informado, no formato definido pelo $X S D$ da seção 4.4.

KFConfig O KFConfig, ou KnowledgeFlow Config é uma representação de objeto do XML de configuração do KnowledgeFlow. Através dos métodos desta classe é possível abstrair todas as dificuldades de se trabalhar diretamente com o arquivo XML. Uma vez que o XML de configuração seja processado pelo KFConfigController toda a informação armazenada no XML é carregada em um objeto desta classe.

KFConfigPiece Cada pedaço do XML de configuração especificado na seção 4.4 herda desta classe. Esta classe fornece a estrutura básica de cada segmento do XML. Ao estabelecermos uma super classe comum a todas as classes de configuração do EasyLearn definimos um padrão que simplifica a escrita e o entendimento do XML de configuração. Cada subclasse de KFConfigPiece é mapeada em um objeto <include> do XML (vide XSD na seção 4.4).

KFConfigPieceSource Corresponde ao bloco <sources> do XML de configuração. Mantém as configurações de todos os DataSources informados no KnowledgeFlow. Ver seção A.4 para mais informações.

KFConfigPiecePriori Corresponde ao bloco <priori> do XML de configuração. Mantém as configurações de todos os pré-processadores informados no KnowledgeFlow. Ver seção A.5 para mais informações.

KFConfigPieceMerger Corresponde ao bloco <merger> do XML de configuração. Responsável por guardar a configuração do agregador de filtros a ser utilizado pelo framework. O conceito de agregador de filtros é explicado na seção A.7.

KFConfigPieceClassifier Corresponde ao bloco <classifiers> do XML de configuração. Mantém as configurações de todos os classificadores informados no KnowledgeFlow. Ver seção A.6 para mais informações.

KFConfigPiecePosteriori Corresponde ao bloco <posteriori> do XML de configuração. Mantém as configurações de todos os pós-processadores informados no KnowledgeFlow. Ver seção A.8 para mais informações.

KFExclusion Corresponde ao bloco <exclusions> do XML de configuração. Mantém as configurações de todos os KFConfigPiece definidos no XML 
de configuração referenciado pelo atributo parent do KnowledgeFlow que devem ser desconsiderados no XML de configuração filho.

ConfigParam A classe KFConfigPiece, consequentemente, todas as classes da sua hierarquia, possuem a capacidade de armazenarem parâmetros de configuração (ConfigParam) do tipo chave-valor. Através destes parâmetros é possível alcançar um nível maior de flexibilidade para o framework. Estes parâmetros são consumidos mais tarde, durante a fase de execução do KnowledgeFlow.

ConfigList Lista de ConfigParam que fornece um conjunto de métodos que simplificam o acesso aos parâmetros de configuração. Todos os parâmetros de configuração vêm do XML como String. Com os métodos da ConfigList podemos recuperar os parâmetros como valores inteiros, booleanos, datas, classes, sem que seja necessário fazer parse da String, já que isto é feito de forma transparente por esta classe. 


\section{A.3}

\section{Pacote Matcher.KFlow}

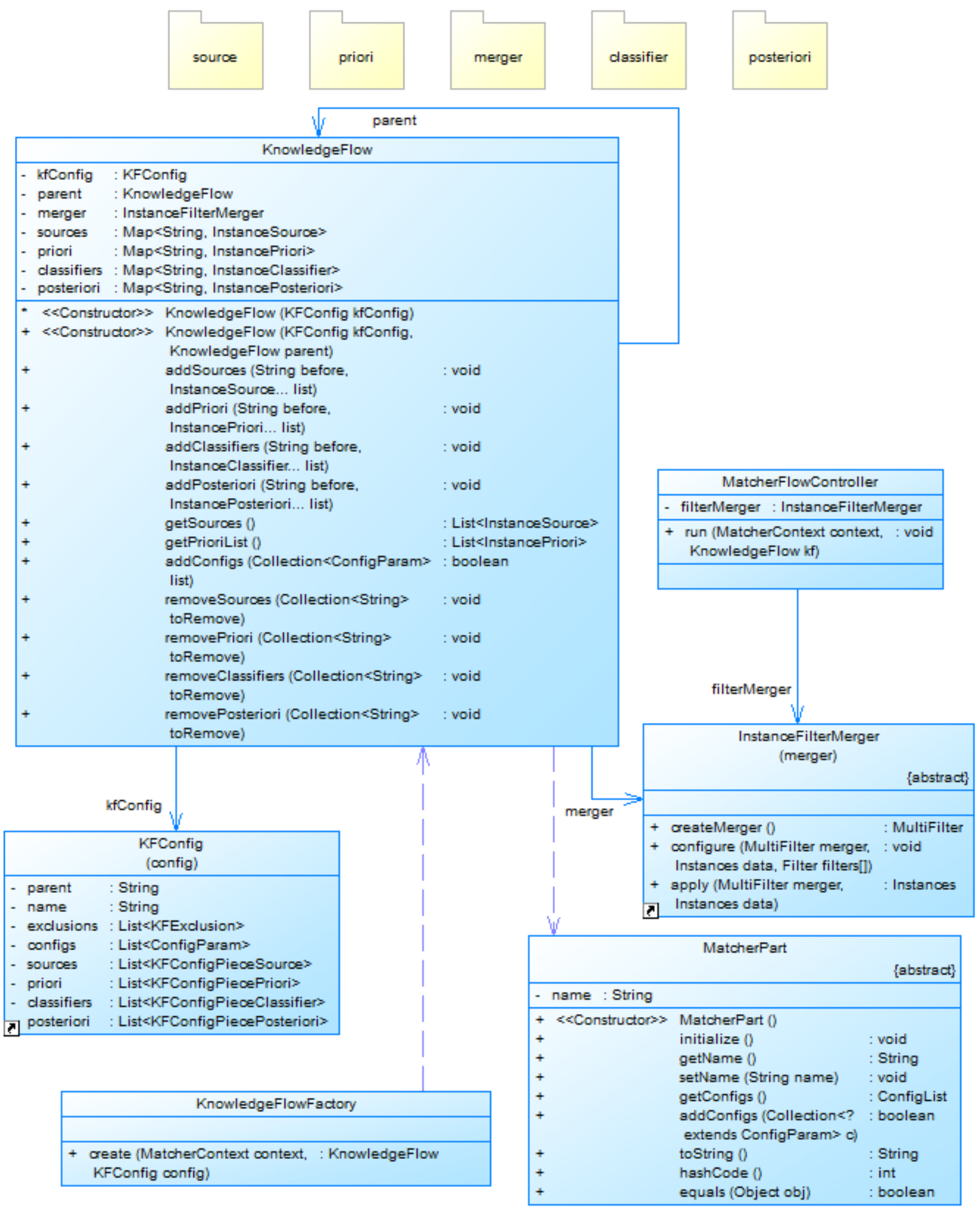

Figura A.3: Diagrama das classes do pacote Matcher.KFlow 
MatcherPart Classe abstrata responsável por fornecer os métodos básicos para todos os objetos que fazem parte da classe KnowledgeFlow. Mantém a lista de parâmetros de configuração (ConfigList carregada no XML de configuração e um atributo name).

KnowledgeFlow . O KnowledgeFlow é construído através de um objeto do tipo KFConfig já carregado com informações do XML de configuração, e, opcionalmente, por um KFConf ig representando o conjunto de configurações do XML raiz (definido pelo atributo parent). Nesta classe é guardado todos os MatcherPart que serão executados pelo MatcherFlowController. Os construtores desta classe são restritos ao pacote Matcher.KFlow (ver KnowledgeFlowFactory).

KnowledgeFlowFactory Implementa o padrão de projeto Factory definido em (Gamma95). A criação de objetos KnowledgeFlow deve ser intermediada por esta classe. Esta classe também é responsável por estabelecer a ordem de junção dos MatcherPart de acordo com o atributo before do <include> (<include before='MatcherPartName' ... >), mantendo a sequência definida pelo usuário da API no momento da criação do XML de configuração, além de habilitar ou desabilitar um MatcherPart pelo atributo enabled (<include ... enabled='false'>).

MatcherFlowController Define um fluxo padrão de execução para cada KnowledgeFlow. Possui um único método: run (MatcherContext, KnowledgeFlow). Além do KnowledgeFlow, o método $\operatorname{run}(\ldots)$ também recebe um MatcherContext que acumula as operações realizadas por cada MatcherPart definida no KnowledgeFlow. Caso seja necessário modificar o controlador de fluxo a ser utilizado, é possível definir um controlador alternativo através do XML de configuração, utilizando o atributo flow. 


\section{A.4}

\section{Pacote Matcher.KFlow.Source}

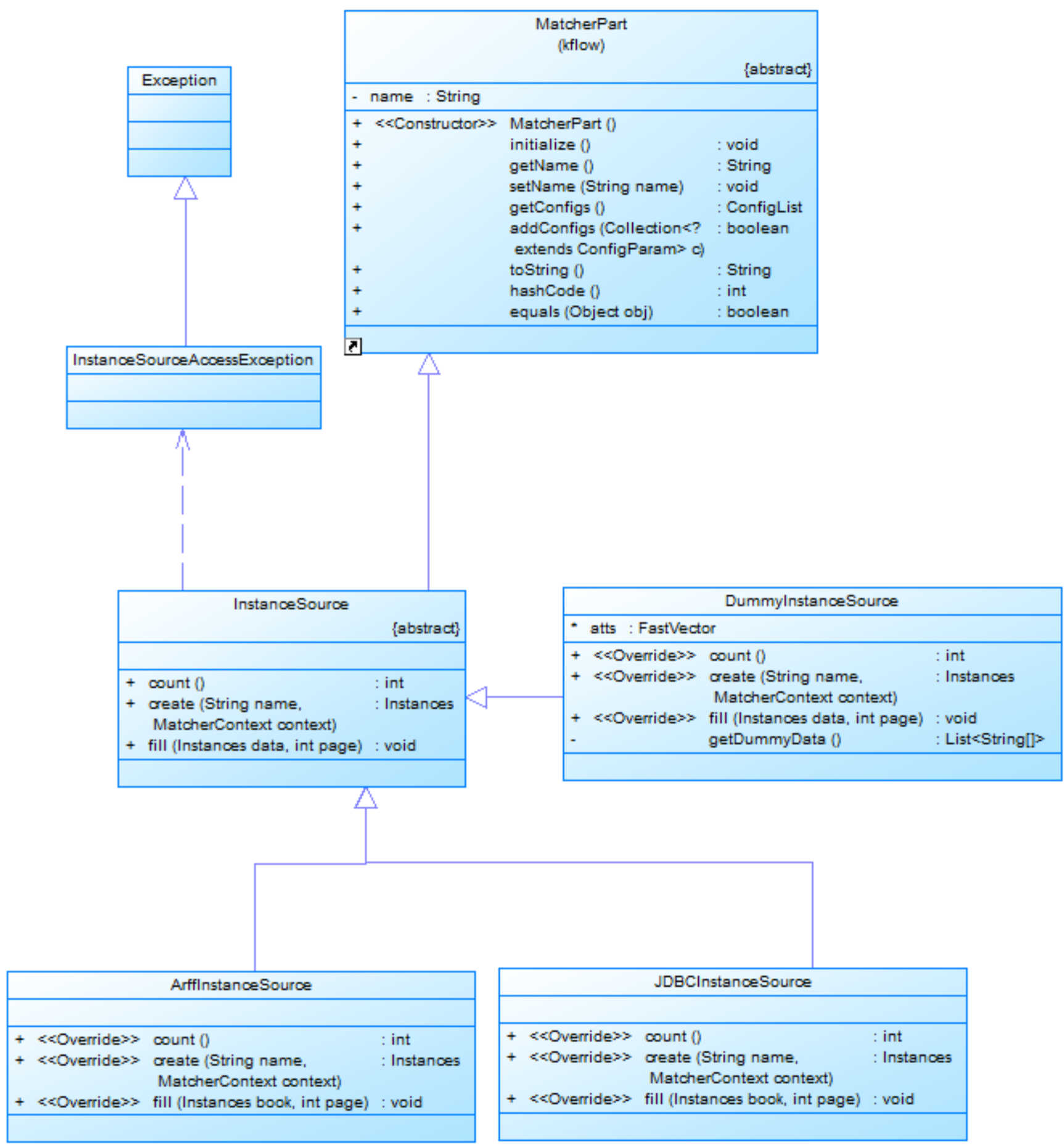

Figura A.4: Diagrama das classes do pacote Matcher.KFlow.Source

InstanceSource Classe abstrata que estabelece os métodos básicos para a criação de componentes para abertura e carregamento de DataSource utilizado no EasyLearn. Os seguintes métodos foram definidos nesta classe: create (...): cria e adiciona o DataSource no MatcherContext recebido 
por parâmetro.

fill (...): carrega os dados referentes à página recebida como parâmetro. count (): retorna o total de páginas do DataSource a ser carregado.

ArffInstanceSource Herda de InstanceSource e carrega o DataSource de um arquivo arff.

Requer os seguintes atributos:

arff: String - caminho relativo ao diretório library do KnowledgeBase do arquivo ARFF (padrão de arquivo de entrada do WEKA) a ser carregado. classIndex: Integer - índice do atributo de classe do DataSource.

JDBCInstanceSource Herda de InstanceSource e carrega o DataSource de um banco de dados qualquer através da API JDBC do Java.

Requer os seguintes atributos:

connString: String - String de conexão ao banco de dados. sql:String - Consulta SQL utilizada para extrair os dados.

DummyInstanceSource Herda de InstanceSource e permite construir um conjunto de dados aleatórios para testes do framework.

InstanceSourceAccessException Cada método de acesso à camada de dados pode lançar uma exceção do tipo InstanceSourceAccessException, seja ao tentar ler de uma base de dados indisponível, ou um arquivo que esteja inacessível, ou qualquer outro motivo. 


\section{A.5}

\section{Pacote Matcher.KFlow.Priori}

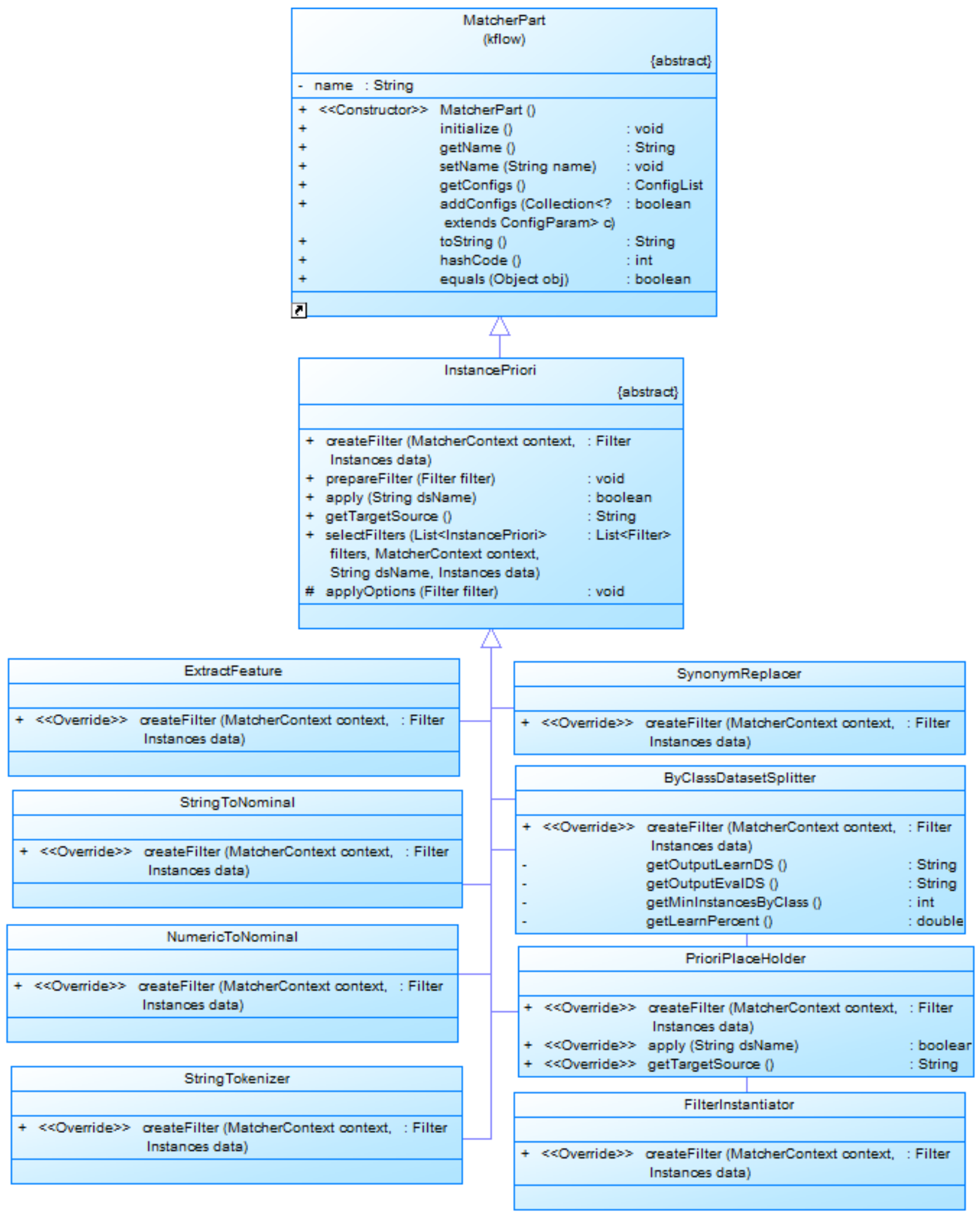

Figura A.5: Diagrama das classes do pacote Matcher.KFlow.Priori 
InstancePriori Classe abstrata que estabelece os métodos básicos para a criação de componentes para pré-processamento do DataSource utilizado no EasyLearn. Os seguintes métodos foram definidos nesta classe:

createFilter (...): implementa o padrão de projeto TemplateMethod de (Gamma95), este método deve configurar e retornar uma implementação da classe Filter do framework WEKA que será utilizado para pré-processar os DataSources.

prepareFilter (...): configura o filtro criado de acordo com o parâmetro facultativo options.

apply (...): retorna true caso o filtro deva ser aplicado para o DataSource corrente.

Parâmetro obrigatório:

targetSource:String - nome do DataSource a ser aplicado o filtro.

Parâmetro facultativo:

options:String [] - lista de parâmetros de configuração do filtro, separados por vírgula.

FilterInstantiator Herda de InstancePriori. Esta classe possibilita ao desenvolvedor carregar e instanciar filtros dinamicamente, através do uso do pacote de reflection do Java.

Parâmetro obrigatório:

type:Class - nome completo da classe a ser carregada. A classe a ser instanciada deve pertencer à hierarquia da classe Filter do WEKA.

StringTokenizer Herda de InstancePriori. Converte um atributo Text do DataSource em uma série de atributos, cada qual, representando uma palavra. O processo de separação das palavras depende do Tokenizer a ser utilizado, e também pode ser configurado através do parâmetro options. Este filtro deve ser aplicado para a construção da Bag of Words explicada na seção 2.4. Cada atributo criado será do tipo Numeric do ARFF.

NumericToNominal Herda de InstancePriori. Após aplicar o filtro StringTokenizer, recomenda-se utilizar o filtro NumericToNominal, pois os atributos gerados após o processo de separação das palavras serão do tipo Numeric, e, nem sempre serão suportados pelo classificador utilizado, dependendo do caso. Este filtro transforma os atributos numéricos especificados, em atributos do tipo Nominal que possuem um conjunto bem definido de valores. 
StringToNominal Herda de InstancePriori. Converte atributos do tipo Text do padrão ARFF, em atributos do tipo Nominal. Esta transformação é imprescindível em alguns casos, especialmente porque a maioria dos classificadores não suportam atributos do tipo Text.

SynonymReplacer Herda de InstancePriori. Substitui sinônimos por palavras correspondentes visando diminuir a dimensão do DataSource, tornando a classificação mais eficiente e simplificando o modelo gerado. Utiliza-se de um dicionário de sinônimos e correspondência de palavras ou termos para realizar esta operação. O dicionário a ser informado deve seguir algumas regras simples. Exemplo:

$$
\begin{aligned}
& \text { ajudar }==\text { auxiliar } \mid \text { socorrer } \\
& \text { codigo }=\backslash \mathrm{bcod}(\backslash d+) \backslash \mathrm{b} \mid \backslash \mathrm{b} \operatorname{cod} \backslash \mathrm{s}(\backslash \mathrm{d}+) \backslash \mathrm{b}
\end{aligned}
$$

Podemos ver pelo exemplo acima duas possíveis entradas para o dicionário de sinônimos. A primeira linha informa ao filtro que devemos substituir as palavras auxiliar e socorrer pela palavra ajudar (utilizando-se "==" representa uma substituição literal). A linha de baixo, informa que devemos realizar a substituição de uma expressão regular (cod seguido de algum número) pela palavra codigo (ao utilizar "=" podemos informar uma expressão regular).

Parâmetros obrigatórios:

dictionary: String - caminho relativo ao diretório library do KnowledgeBase do arquivo de dicionário a ser carregado.

targetIndex: Integer - índice do atributo alvo a ser aplicado o filtro.

ExtractFeature Herda de InstancePriori. Extrai um novo atributo Nominal para o DataSource, tomando como base algum atributo do tipo Text do ARFF. Este pré-processador utiliza-se de um dicionário de termos, e faz uma busca em cada palavra do atributo alvo, caso haja alguma palavra que esteja contida no dicionário de termos, esta palavra vira valor do atributo a ser criado.

Parâmetros obrigatórios:

dictionary: String - caminho relativo ao diretório library do KnowledgeBase do arquivo de dicionário a ser carregado.

newFeatureName:String - nome do novo atributo a ser criado no DataSource.

targetFeatureName:String - nome atributo alvo a ser aplicado o filtro. 
ByClassDatasetSplitter Herda de InstancePriori. Auxilia na quebra do DataSource definido pelo atributo targetSource em DataSource de treino e DataSource de avaliação, seguindo algumas regras básicas.

Parâmetros obrigatórios:

outLearnSource: String - nome do DataSource de treino a ser criado pelo filtro.

outEvalSource:String - nome do DataSource de avaliação a ser criado pelo filtro.

minInstancesByClass:Integer - quantidade mínima de instâncias que cada classe deve possuir para ser incluída nos DataSources de saída. Classes que não atinjam esta quantidade de instâncias serão eliminadas no output gerado.

learnPercent:Double - percentual aproximado do tamanho do DataSource de treino em relação ao DataSource de avaliação.

PrioriPlaceHolder Esta classe não possui implementação e não interfere no DataSource. Ela é utilizada apenas para facilitar a criação de arquivos de configuração que possuem uma hierarquia mais complexa. Através do place holder é possível "reservar" um espaço no arquivo de configuração do XML pai, facilitando a inserção de outros elementos no XML filho na posição correta. 


\section{A. 6}

\section{Pacote Matcher.KFlow.Classifier}

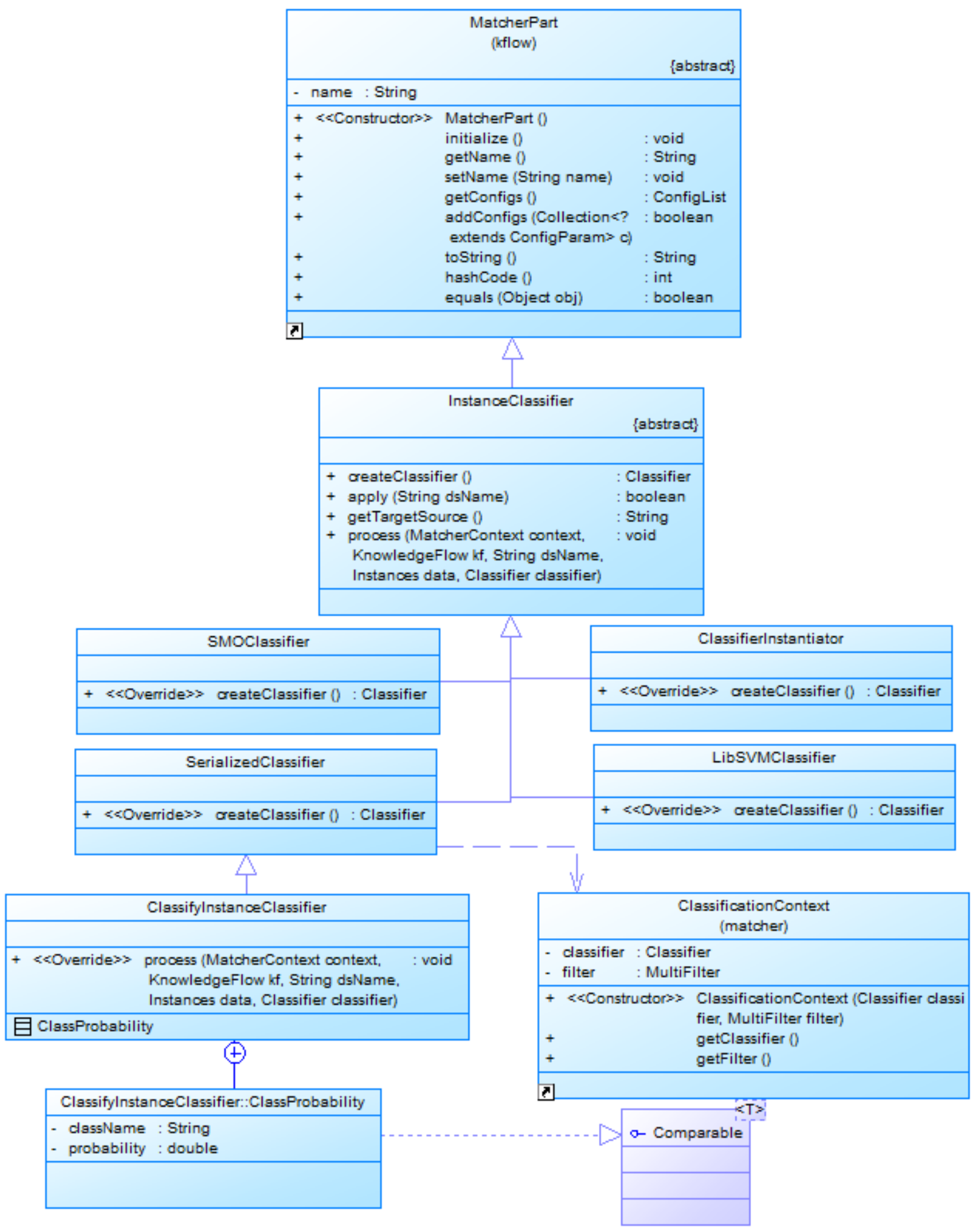

Figura A.6: Diagrama das classes do pacote Matcher.KFlow.Classifier 
InstanceClassifier Classe abstrata que estabelece os métodos básicos para a criação de componentes para classificação do DataSource utilizado no EasyLearn. Os seguintes métodos foram definidos nesta classe:

createClassifier(): implementa o padrão de projeto TemplateMethod de (Gamma95), este método deve configurar e retornar uma implementação da classe Classifier do framework WEKA que será utilizado para classificar os DataSources.

apply (...): retorna true caso o classificador deva ser aplicado para o DataSource corrente.

process (... ) : realiza a classificação sobre o DataSource alvo, o resultado da classificação deve ser adicionado dentro do MatcherContext para acesso futuro por outras etapas do fluxo de execução do KnowledgeFlow.

Parâmetro obrigatório:

targetSource:String - nome do DataSource a ser aplicado o classificador.

ClassifierInstantiator Herda de InstanceClassifier. Esta classe possibilita ao desenvolvedor carregar e instanciar classificadores dinamicamente, através do uso do pacote de reflection do Java.

Parâmetro obrigatório:

type:Class - nome completo da classe a ser carregada. A classe a ser instanciada deve pertencer à hierarquia da classe Classifier do WEKA.

SMOClassifier Herda de InstanceClassifier. Carrega e configura o algoritmo de classificação SMO que é a implementação do classificador SVM.

Parâmetro facultativo:

c:Double - parâmetro de complexidade do algoritmo SVM.

LibSVMClassifier Herda de InstanceClassifier. Carrega e configura o algoritmo de classificação SVM utilizando uma implementação mais eficiente do framework LibSVM.

Parâmetro facultativo:

c:Double - parâmetro de complexidade do algoritmo SVM.

SerializedClassifier Herda de InstanceClassifier. Carrega um ClassificationContext serializado do diretório classifier da KnowledgeBase.

Parâmetro obrigatório:

fileName:String - caminho relativo ao diretório classifier do KnowledgeBase do arquivo do classificador serializado a ser carregado. 
ClassifyInstanceClassifier Herda de SerializedClassifier. Este classificador é utilizado ao final do processo de classificação 3.4 para processar o DataSource contendo os dados reais. Ao final da execução deste classificador, o MatcherContext é atualizado para guardar o resultado da classificação. Para cada instância classificada é criado uma lista de objetos do tipo ClassProbability que guarda o palpite da classe relativa àquela instância, e um double representando a certeza daquele palpite (probabilidade). 


\section{A.7}

\section{Pacote Matcher.KFlow.Merger}

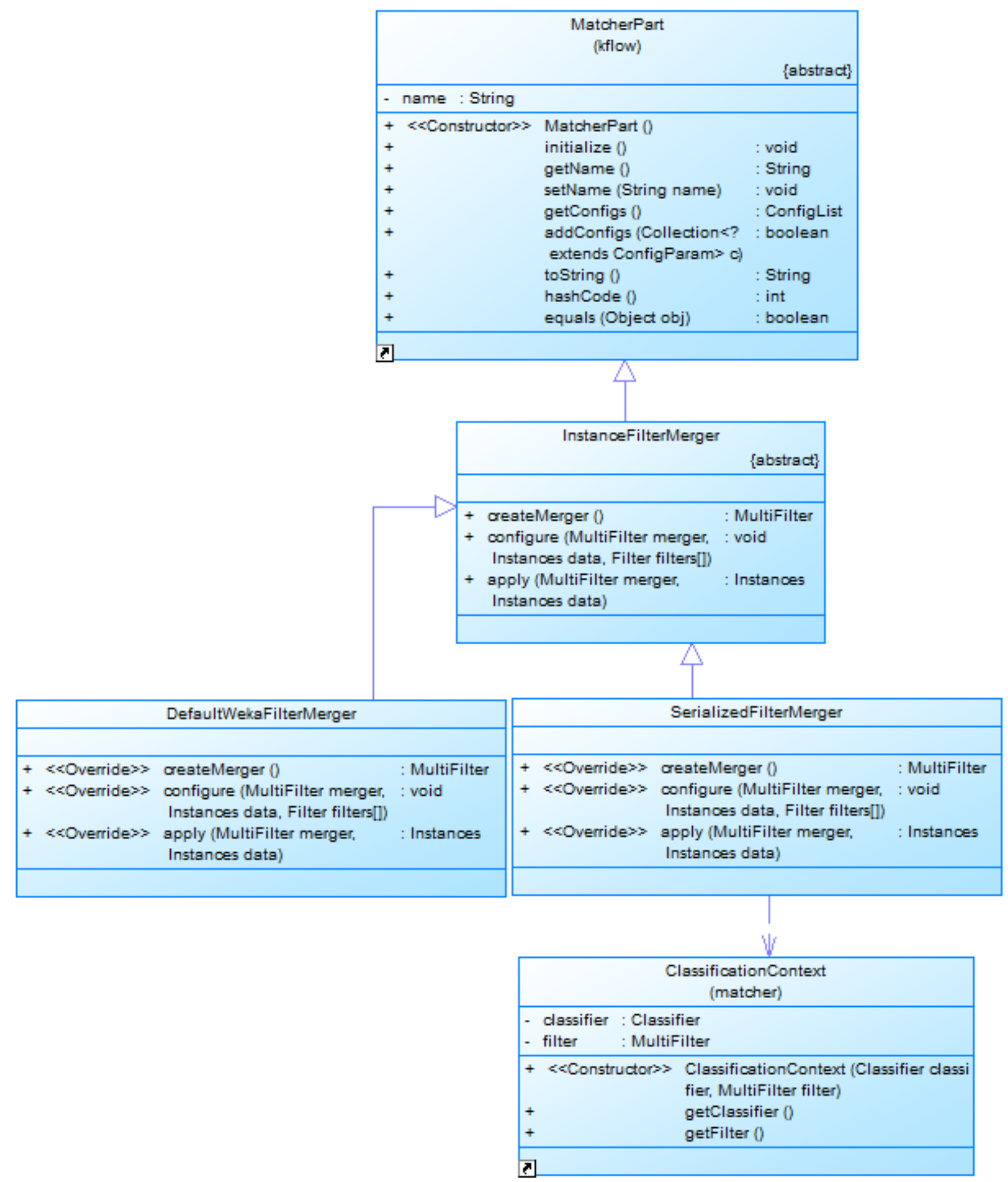

Figura A.7: Diagrama das classes do pacote Matcher.KFlow.Merger

InstanceFilterMerger Classe abstrata que estabelece os métodos básicos para a criação de componentes para pré-processamento em lote do DataSource utilizado no EasyLearn. Os seguintes métodos foram definidos nesta classe: 
createMerger(): implementa o padrão de projeto TemplateMethod de (Gamma95), este método deve configurar e retornar uma implementação da classe MultiFilter do framework WEKA que será utilizado para préprocessar de forma mais eficiente os DataSources.

apply $(. .$.$) : recebe um dataset bruto e aplica o conjunto de pré-$ processadores, retornando um novo dataset pronto para a classificação.

DefaultWekaFilterMerger Herda de InstanceFilterMerger. Implementação padrão de FilterMerger utilizando o MultiFilter do WEKA.

SerializedFilterMerger Herda de InstanceFilterMerger. Carrega um ClassificationContext serializado do diretório classifier da KnowledgeBase e utiliza o FilterMerger do ClassificationContext para realizar o pré-processamento. Desta forma, garantimos que o mesmo conjunto de operações aplicados no dataset durante o processo de Aprendizado também será aplicado durante a fase de classificação - assegurando que os datasets vão possuir a mesma estrutura ao final do processamento e evitando inconsistências e incompatibilidades entre eles. 


\section{A.8}

\section{Pacote Matcher.KFlow.Posteriori}

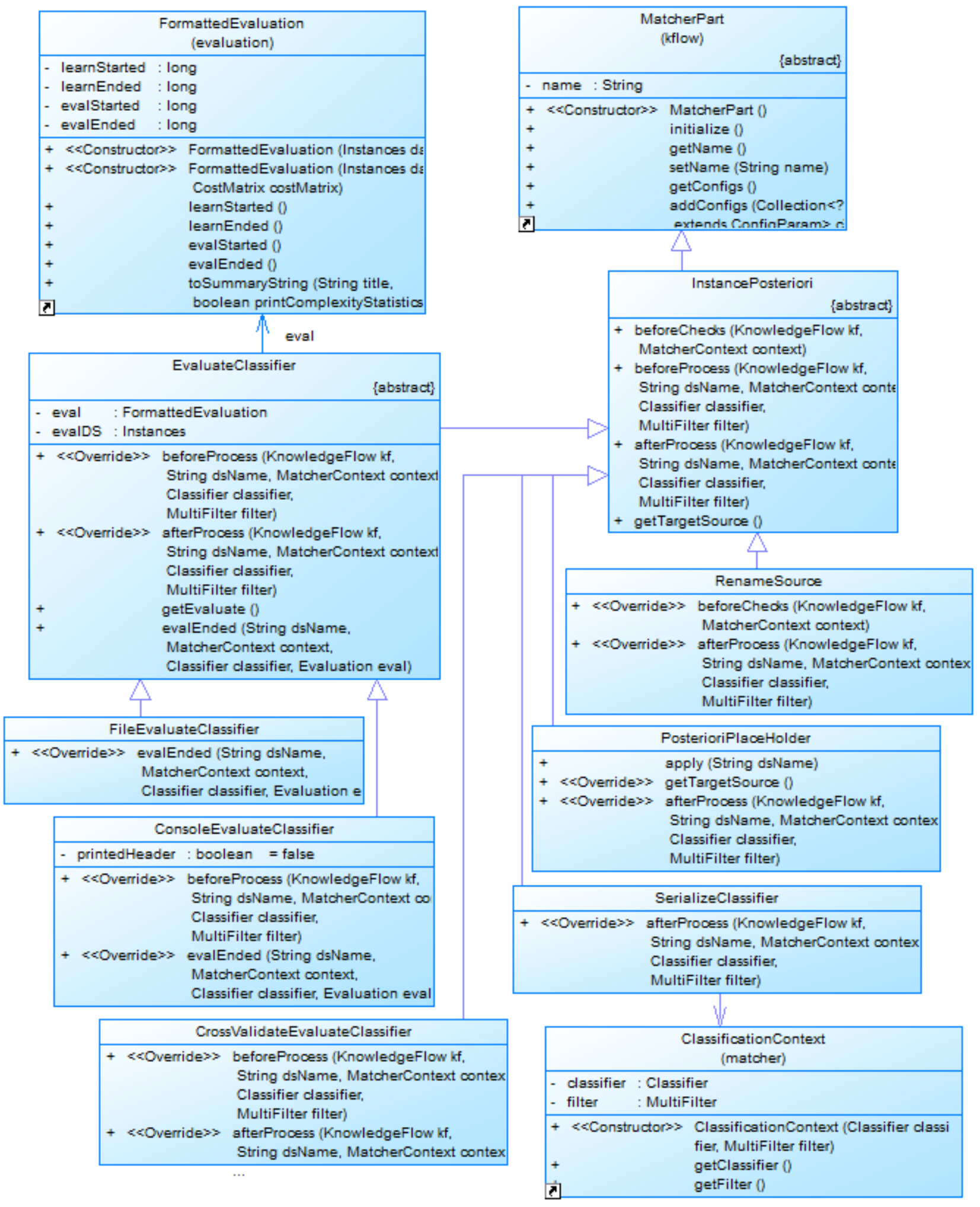

Figura A.8: Diagrama das classes do pacote Matcher.KFlow.Posteriori 
InstancePosteriori Classe abstrata que estabelece os métodos básicos para a criação de componentes para pós-processamento do DataSource utilizado no EasyLearn. Os seguintes métodos foram definidos nesta classe:

beforeChecks (...): evento acionado pelo controlador de fluxo antes do processo de validação do MatcherContext.

beforeProcess (...): evento acionado pelo controlador de fluxo antes do processo de classificação.

afterProcess (...): evento acionado pelo controlador de fluxo após o processo de classificação.

Parâmetro obrigatório:

targetSource:String - nome do DataSource a ser aplicado o pósprocessador.

EvaluateClassifier Herda de InstancePosteriori e utiliza a classe Evaluation do WEKA para realizar as avaliações de precisão e tempo gasto para treinamento e classificação. Parâmetro obrigatório: evalSource:String - nome do DataSource de avaliação a ser utilizado.

ConsoleEvaluateClassifier Herda de EvaluateClassifier e imprime no console do sistema a saída do processo de avaliação.

Cross ValidateEvaluateClassifier Herda de EvaluateClassifier e realiza a validação cruzada no DataSource especificado pelo parâmetro evalSource. Parâmetro obrigatório:

folds: Integer - permite definir a quantidade de iterações do processo de validação cruzada.

FileEvaluateClassifier Herda de EvaluateClassifier e salva em um arquivo a saída do processo de avaliação. Parâmetro obrigatório:

file:String - nome do arquivo de destino, relativo ao diretório reports da KnowledgeBase.

PosterioriPlaceHolder Esta classe não possui implementação e não interfere no DataSource. Ela é utilizada apenas para facilitar a criação de arquivos de configuração que possuem uma hierarquia mais complexa. Através do place holder é possível "reservar" um espaço no arquivo de configuração do XML pai, facilitando a inserção de outros elementos no XML filho na posição correta.

RenameSource Herda de EvaluateClassifier e renomeia um DataSource no MatcherContext. Eventualmente é necessário renomear o DataSource 
em um XML de configuração para atender à algum nome específico do XML de configuração definido pelo atributo parent.

Parâmetro obrigatório:

newSource:String - novo nome do DataSource alvo.

SerializeClassifier Herda de EvaluateClassifier e persiste um classificador no diretório classifiers da KnowledgeBase para usos futuros.

Parâmetro obrigatório:

file:String - nome do arquivo de destino, relativo ao diretório classifiers da KnowledgeBase. 


\section{A.9}

\section{Pacote Matcher.Weka.Filter}

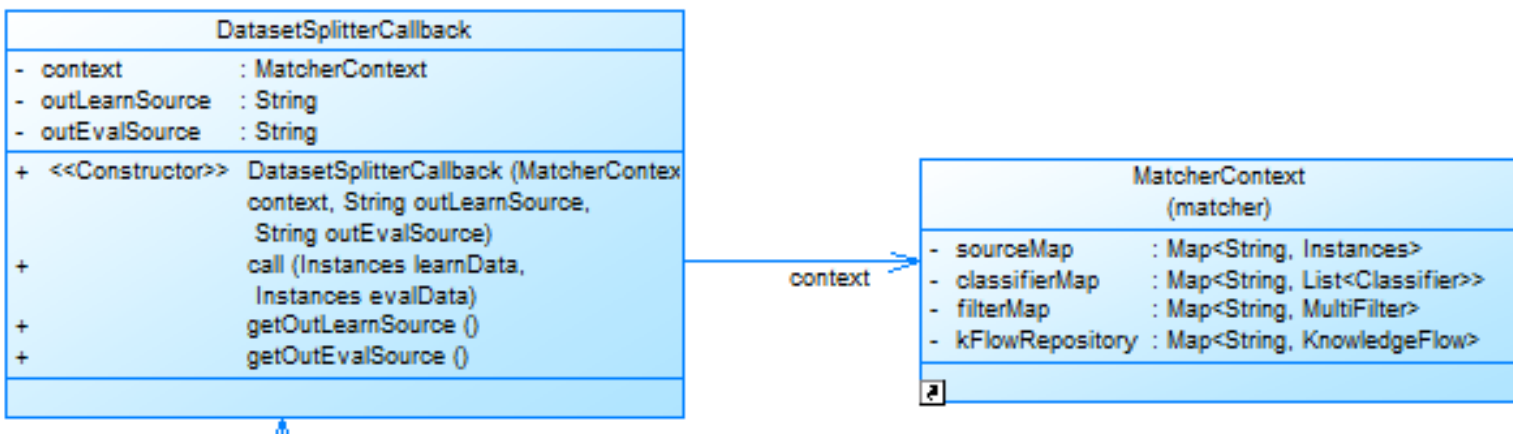

\begin{tabular}{|ll|}
\hline \multicolumn{2}{|c|}{ ByClassDatasetSplitterFilter } \\
\hline - minlnstances & int \\
- learnPercent & : double \\
- callback & : DatasetSplitterCallback \\
\hline+ <Constructor $>$ & ByClassDatasetSplitterFilter (DatasetS \\
& itterCallback callback, \\
& int minInstances, double learnPercent) \\
+ & globallnfo 0 \\
+ & getCapabilities 0 \\
\hline & \\
\hline
\end{tabular}

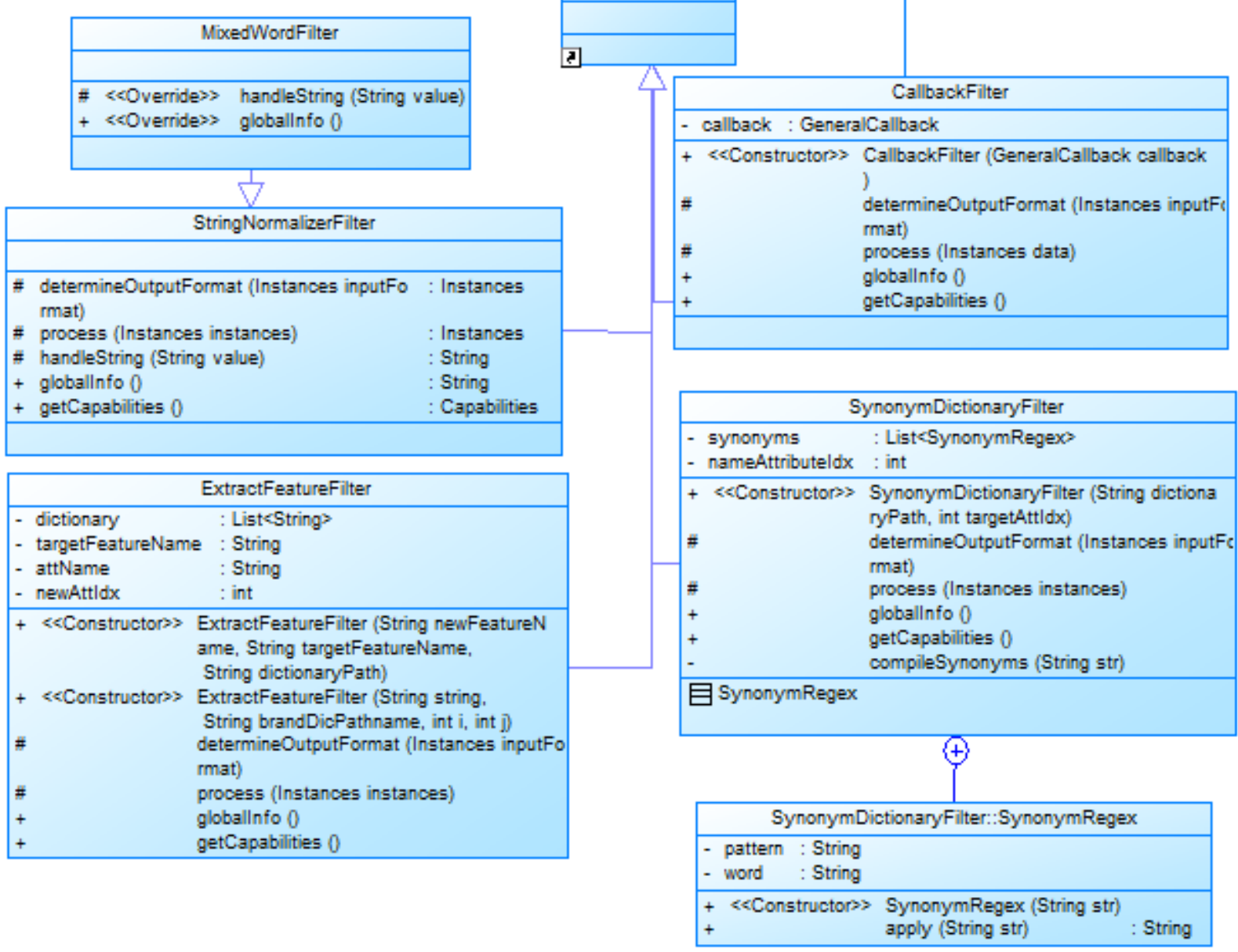

Figura A.9: Diagrama das classes do pacote Matcher.Weka.Filter 
CallbackFilter O processo de pré-processamento é conduzido pelo WEKA, e por isto, temos pouca interferência sobre ele. $\mathrm{O}$ CallbackFilter, é um filtro que permite cadastrar uma função de retorno (callback), onde podemos realizar ações antes ou depois da execução de algum filtro, dando mais controle sobre o processo do WEKA. Herda da classe SimpleBatchFilter do WEKA.

GeneralCallback Interface que define o contrato da função de retorno do CallbackFilter.

ByClassDatasetSplitterFilter Herda da classe SimpleBatchFilter do WEKA, e é onde ocorre o processamento da classe ByClassDatasetSplitter (seção A.5).

DatasetSplitterCallback Herda da interface GeneralCallback. Possui a implementação da função de Callback da classe ByClassDatasetSplitterFilter, chamada ao final do processamento para atualizar o MatcherContext com o resultado do filtro.

ExtractFeatureFilter Herda da classe SimpleBatchFilter do WEKA, e é onde ocorre o processamento da classe ExtractFeature (seção A.5).

StringNormalizerFilter Herda da classe SimpleBatchFilter do WEKA. Contém algumas regras básicas para tratamento de strings, tais como, padronização de case (todas as palavras são colocadas em minúsculo ou maiúsculo) e remoção de acentuação e caracteres especiais.

MixedWordFilter Herda da classe StringNormalizerFilter. Separa palavras que contenham letras e números e várias palavras. Exemplo: a palavra SAMSUNG5500DX será separada em \{SAMSUNG, 5500, DX\}.

SynonymDictionaryFilter Herda da classe SimpleBatchFilter do WEKA, e é onde ocorre o processamento da classe SynonymReplacer (seção A.5). 
A.10

Pacote Matcher.Weka.Evaluation

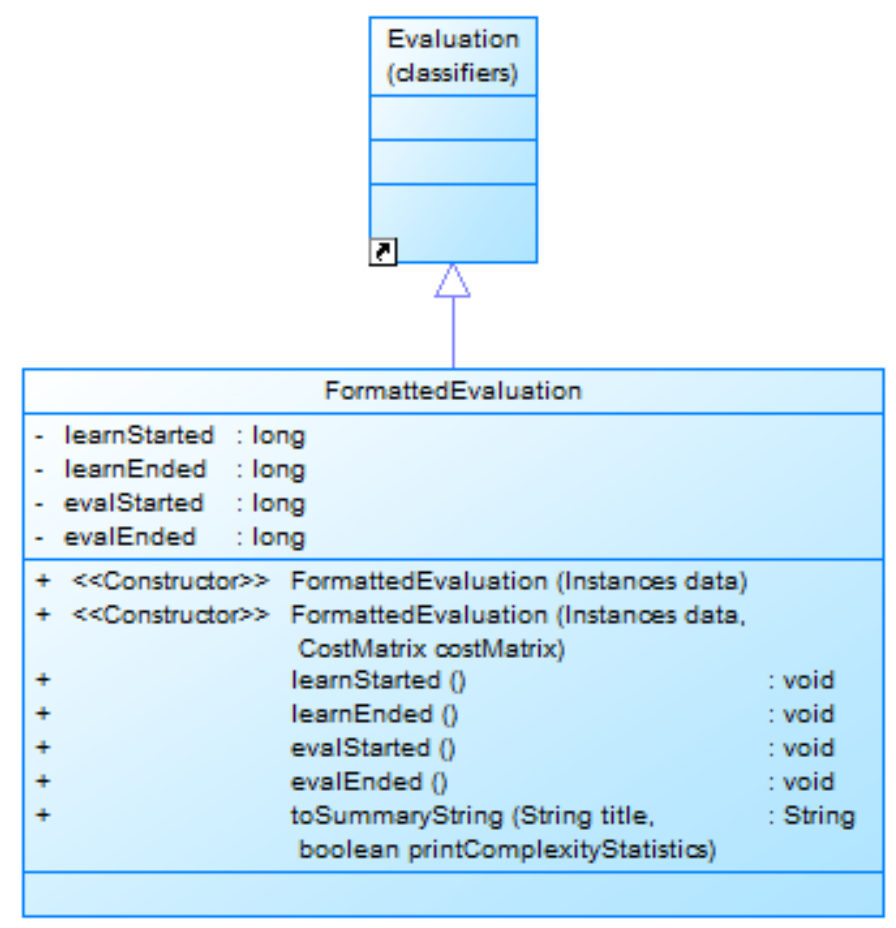

Figura A.10: Diagrama das classes do pacote Matcher.Weka.Evaluation

FormattedEvaluation Permite visualizar as informações do processo de avaliação de forma simplificada e padronizada, exibindo o resultado de cada classificador por linha. 


\section{A.11}

\section{Pacote Debug}

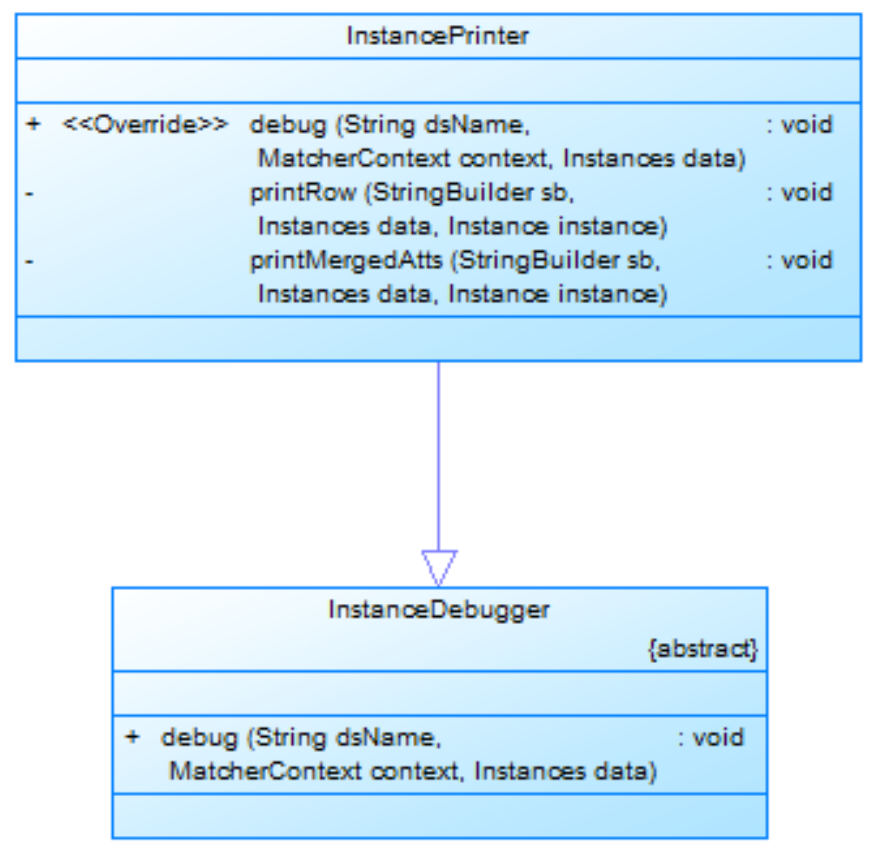

Figura A.11: Diagrama das classes do pacote Matcher.Debug

InstanceDebugger Intercepta cada parte do fluxo de execução, facilitando o processo de debugging do framework.

InstancePrinter Permite imprimir o estado atual do MatcherContext para fins de debug. 


\section{B}

\section{XML de Configuração: SPAM}

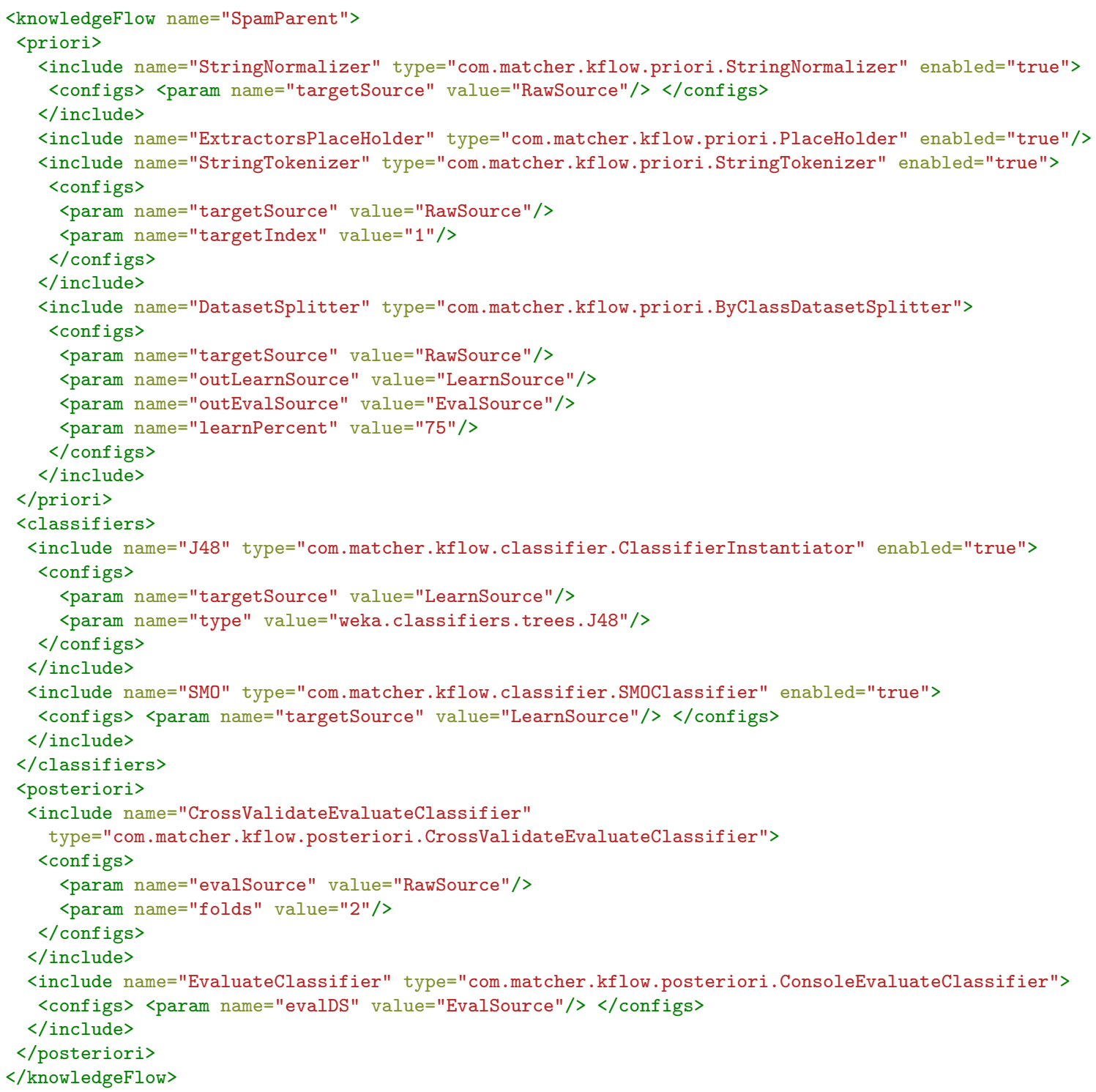

Listing 1: SpamParent: XML de configuração raiz 


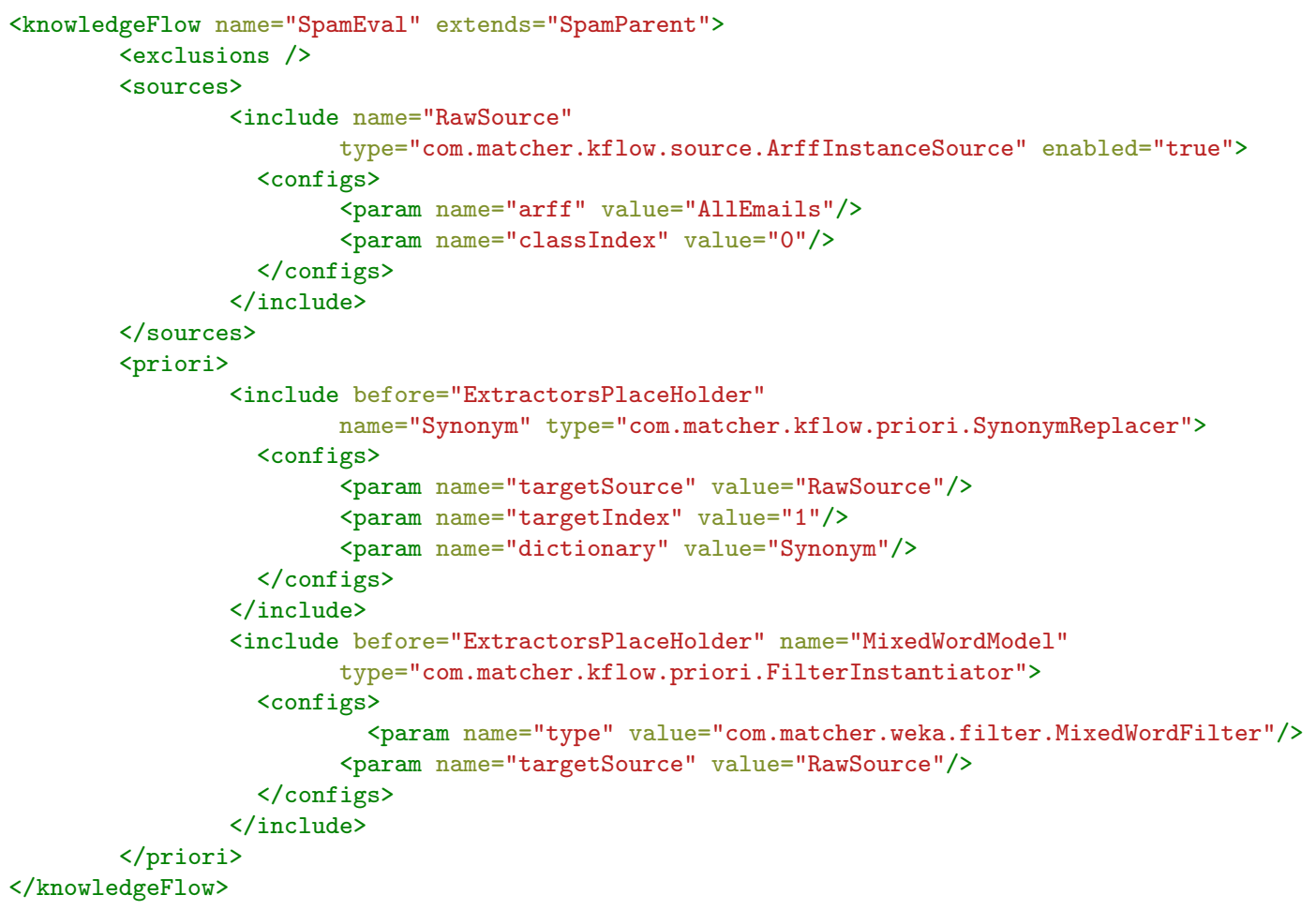

Listing 2: SpamEval: XML de configuração do processo de avaliação

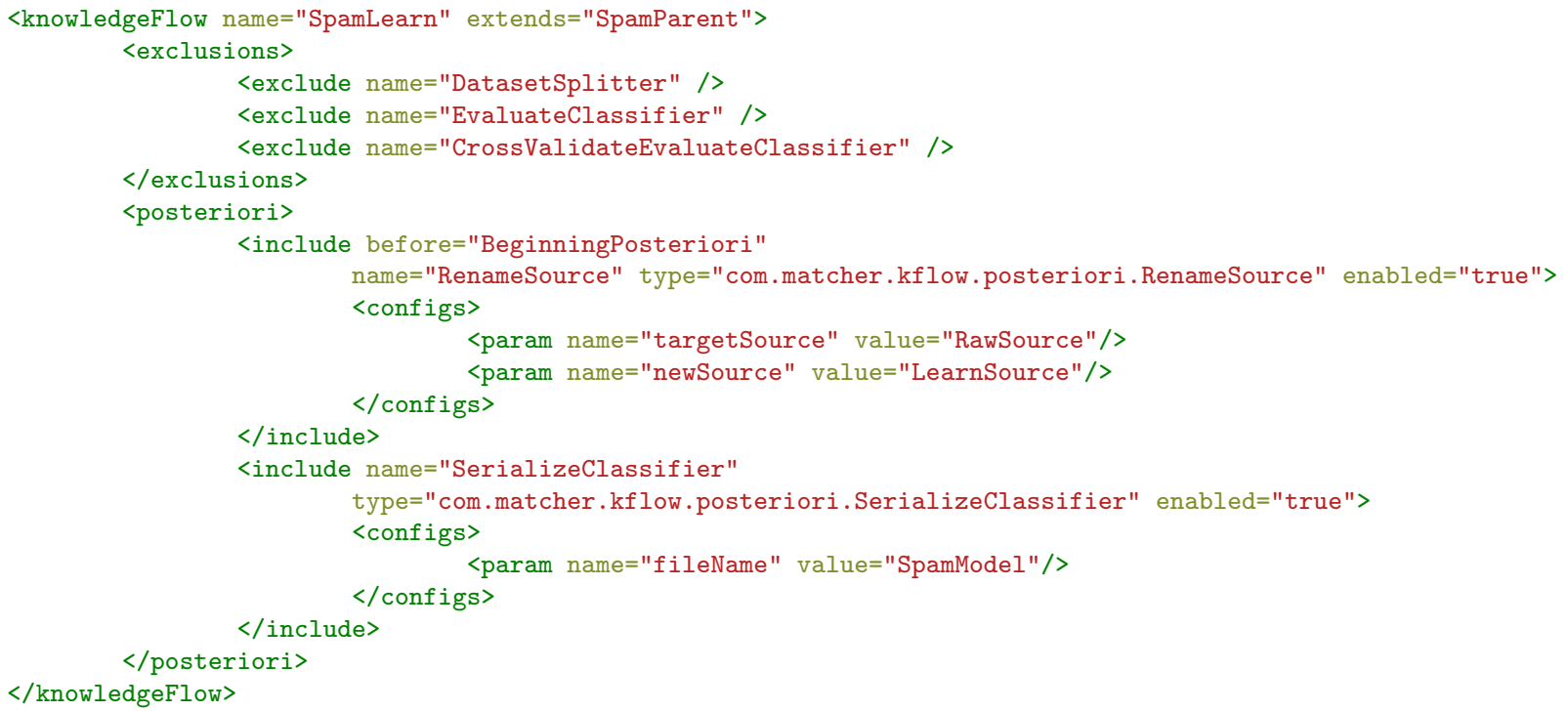

Listing 3: SpamLearn: XML de configuração do processo de aprendizado 


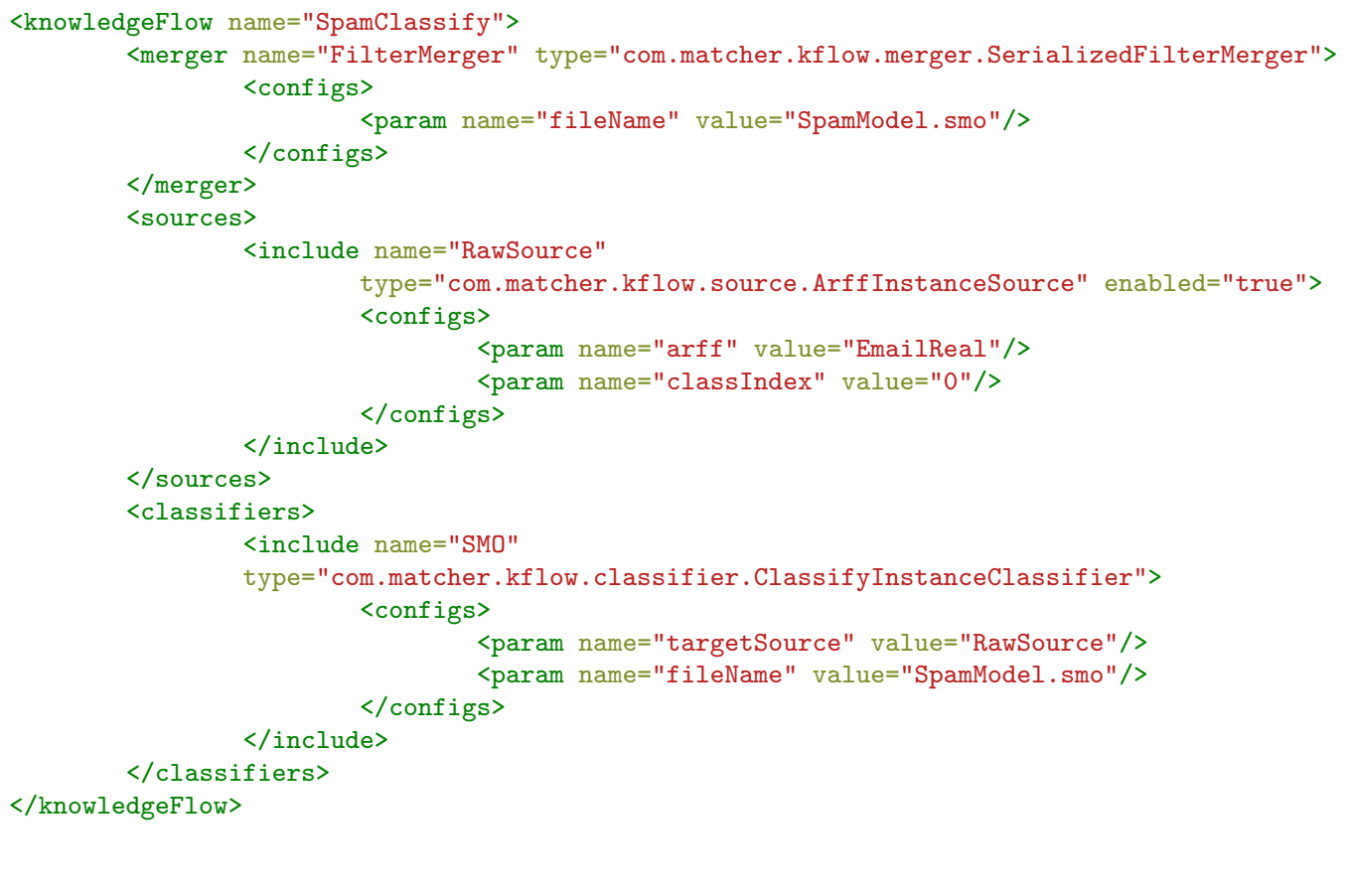

Listing 4: SpamClassify: XML de configuração do processo de classificação 